Article

\title{
Can Spectrophotometry Be Used to Quantify Zingiberene Ses- quiterpenoids in Tomato Leaflet Extracts?
}

\author{
Mohammad Dawood ${ }^{1}$ and John C.C. Snyder $2, *$ \\ 1 University of Kufa, College of Agriculture, Department of Soil Science and Water Resources, El-Najaf 54003, \\ Iraq; mohakent2015@gmail.com \\ 2 University of Kentucky, Department of Horticulture, Lexington, KY 40503; snyder@uky.edu \\ * Correspondence: snyder@uky.edu; Tel.: 1-859-257-5635
}

\begin{abstract}
Tomato (Solanum lycopersicum), an important vegetable crop, is a host for numerous pests and pathogens. Consequently, tomato breeders are striving to improve pest resistance. Many accessions of the wild relative $S$. habrochaites display high resistance towards arthropod pests such as spider mites and whiteflies and the presence of the sesquiterpene hydrocarbon 7-epi-zingiberene on its trichomes has been associated with arthropod resistance. Consequently, tomato breeders are attempting to introgress 7-epi-zingiberene from wild to cultivated tomato. 7-epi-zingiberene has conjugated double bonds causing it to absorb UV light. In fact, absorbance at $270 \mathrm{~nm}$ of tomato leaflet washes has been used to aid introgression, but its use has not been critically evaluated. Consequently, we evaluated the relationships between UV absorbances in the 200-350 nm range and the concentration of 7-epi-zingiberene in plants from several interspecific hybrid generations of tomato. We also evaluated the absorbance spectra for isolated 7-epizingberene and it two oxidized forms. The wavelength of maximum absorbance of the isolated compounds was $264 \mathrm{~nm}$. The strength of the relationship $\left(R^{2}\right)$ between absorbance measured at a single wavelength and quantity zingiberene ranged from 0.30 to 0.92 among generations evaluated. Additionally, the regressions of absorbance at a single wavelength on quantity always resulted in a non-zero intercept, indicating that single wavelength absorbance cannot be directly used for quantitation. Use of multiple wavelengths for quantitation was explored and their use can improve accuracy of quantitation. Measuring absorbance at multiple wavelengths or scanning in the UV range, backstopped by a method of quantitation such as gas chromatography could be a useful tool for aiding introgression.
\end{abstract}

Keywords: tomato, 7-epi-zingiberene, 9-hydroxy-zingiberene, 9-hydroxy-10,11-epoxy zingiberene, spectrophotometer, absorbance, introgression, breeding, wild relatives

\section{Introduction}

The sesquiterpene hydrocarbon zingiberene, $\mathrm{C}_{15} \mathrm{H}_{24}$, is a semi-volatile compound and a major component of the essential oil obtained from roots of ginger [1]. This oil has been of scientific interest since 1853 [2]. The structure of zingiberene was first elucidated by Eschenmoser and Schinz in 1950 [3]. Zingiberene may have medicinal uses since it is a major component of ginger oil which reportedly has an array of health benefits including antibacterial, antifungal, analgesic, anti-inflammatory and anti-ulcer activities, and effects as a immunomodulator, relaxant, and for warming effects [4].

The occurrence of zingiberene is not confined to the ginger family, Zingiberaceae. Zingiberene can also be found in the plant families of Salicaceae [5], Verbenaceae [6], Apiaceae [7], Acanthaceae [8], Rubiaceae [8], Poaceae [9] [10], Asteraceae [11] and Moraceae[12]. It is also present in wild relatives of tomato (Solanaceae), the primary target of this research.

The occurrence of zingiberene in wild tomatoes is of particular interest with regard to genetic improvement of cultivated tomato. Zingiberene in wild tomato was first identified in 1985 [13]. Zingiberene, specifically 7-epi-zingiberene (Figure 1), produced by wild 
tomato is a diastereoisomer of that present in ginger [14]. In the wild tomato it is produced in glandular trichomes by the action of sesquiterpene synthase on $2 z, 6 z$-farnesyl pyrophosphate [15].

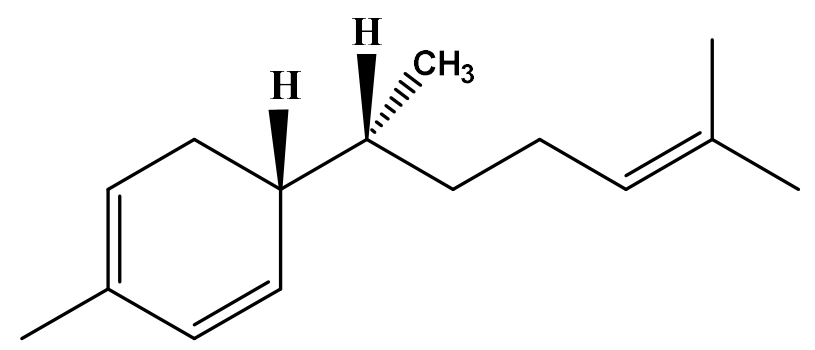

Figure 1. Structure of 7-epi-zingiberene $\left(\mathrm{C}_{15} \mathrm{H}_{24}\right)$ showing the conjugated double bonds in the ring.

The 7-epi-zingiberene that is present in trichomes of wild tomato is an important allelochemical and a natural volatile compound [16]. It is a monocyclic sesquiterpene with toxic and repellent properties on an array of arthropods [17-27], including whiteflies, aphids, and spider mites. 7-epi-zingiberene has three double bonds and the two in the ring are conjugated. These conjugated systems have a large impact on spectral absorbance modifying both wavelength of maximum absorption $(\lambda \max )$ and intensity especially in UV range [28,29].

Tomato (S. lycopersicum) is a host for numerous pests and pathogens [30]. Tomato breeders have focused on increasing fruit quantity and quality with little focus on enhancing resistance to arthropods [31]. As a result, tomato plants are vulnerable to pest attacks throughout the crop cycle; thus, it is necessary to find a way to avoid damage that can reduce yield. Insecticide sprays are the predominant method used for pest control. The use of chemical pest control can, however, cause serious damage and deleterious effects on growers, the health of consumers and can increase in production costs [32-34].

Certain accessions of the wild tomato $S$. habrochaites are highly resistant to a wide range of arthropods in part because the foliage of these accessions contains high levels of allelochemicals such as 7-epi-zingiberene. It may be possible to improve the pest resistance of cultivated tomato by introgression of the presence of 7-epi-zingiberene from wild to cultivated tomato. However, the breeding activity of introgression requires a method of selection for the presence and abundance of this allelochemical. A selection method, especially one that can rapidly quantify allelochemicals responsible for deterring pests could be a valuable tool for aiding the development of new arthropod-resistant cultivars [21,35-37]. The ultimate aim would be to transfer the responsible compounds present in trichomes of wild relatives to cultivated tomato [38].

There are several methods for quantifying 7-epi-zingiberene. One option is gas chromatography [39-43]. However, this method is relatively expensive, somewhat slow and may not be accessible or affordable in plant breeding programs. Because of the presence of conjugated double bonds in 7-epi-zingiberene, it may be possible to quantify it by spectrophotometry in a fashion similar to that used for $\beta$-phellandrene[44,45]. If so, spectrophotometric quantification of 7-epi-zingiberene could be a convenient approach that might be used by plant breeders to transfer this trait to cultivated tomato, leading to tomato cultivars that are resistant to arthropods [23,24]. In fact, Freitas, et al. [46] have reported the use of a spectrophotometric procedure for aiding the selection of tomato genotypes having high concentrations of 7-epi-zingiberene. However, it appears that this method has not been fully evaluated for effects of interfering substances or for its ability to estimate actual concentrations of zingiberene (quantitation). For example, in tomato breeding studies involving introgression of zingiberene based on spectrophotometric readings, parental levels of zingiberene, as indicated by absorbance at $270 \mathrm{~nm}$, were not recovered in any of the reported interspecific hybrids [31,47]. This outcome could be explained by incomplete introgression of the high zingiberene concentration phenotype or could be related to the presence of compounds in the wild donor parent that also 
contribute to absorbance but are not present in offspring. The latter hypothesis is more likely because in contrast to the results of Freitas, Maluf, das Graças Cardoso, Gomes and Bearzotti [46], Snyder, Dawood and Al-Bayati [27], have consistently recovered parental levels of zingiberene in interspecific offspring when the quantitation of 7-epi-zingiberene was based on gas chromatography.

The presence of oxidized forms of 7-epi-zingiberene in trichome secretions could interfere with detection and quantitation of 7-epi-zingiberene by spectrophotometry. Oxidized sesquiterpenoids, mainly carboxy acids of sesquiterpenes have been documented in $S$. habrochaites, often as predominate components of trichome secretions $[48,49]$. The wild tomato accession LA2329, the donor parent for our breeding population, has three major allelochemical components, 7-epi-zingiberene, 9-hydroxy-zingiberene and 9-hydroxy-10,11-epoxy-zingiberene in its trichome secretions. The latter two compounds are oxidized forms of 7-epi-zingiberene. Each of these compounds contains conjugated double bonds in their chemical structures [21]. Because 7-epi-zingiberene absorbs light in the UV region, it is likely these oxidized sesquiterpenoids will also absorb UV light.

The present research was intended to evaluate a spectrophotometric method for estimating 7-epi-zingiberene contents on leaves of interspecific tomato hybrids for potential use in breeding of tomato with arthropod resistance. The primary benefits of using a spectrophotometric method are mainly related to increased throughput and reduced cost, compared to chromatography-based methods. However, use of a spectrophotometer could be problematic when non-target substances also contribute to spectrophotometric absorbance. Therefore, the objective of this research was to evaluate and validate, if possible, the use of a spectrophotometer as a selection tool for identifying and quantifying 7epi-zingiberene in several generations of an interspecific hybrid tomato population that are segregating for presence and abundance of 7-epi-zingiberene as well as for other potentially interfering substances.

\section{Materials and Methods}

This experiment was conducted at the Horticulture Department, University of Kentucky and at the Horticulture Research Farm, Lexington, KY. Plants of S. habrochaites used in this research included representatives of the accessions LA1777, LA2329, and LA2167, all obtained from the Tomato Genetics Resource Center, Davis CA. The S. habrochaites accession PI127826 was originally obtained from the USDA - ARS, Plant Genetic Resources Unit Geneva, NY. Two chemotypes of LA2329, LA2329-A and LA2329-B, were used in this research and their development and characterization are described in Dawood and Snyder [21]. The majority of the research reported herein relied on interspecific hybrid populations (BC3F5, BC4F2 and BC5F1) that resulted from initial crosses between S. habrochaites LA2329 and S. lycopersicum Zaofen 2, which was also the recurrent parent used in the backcross scheme. Zaofen 2 is a determinate, early, soft-fruited tomato cultivar released in the 1960's. The breeding scheme used was a modified backcross design [50]. The other generation used, a BC2F3 generation. was a complex hybrid between Zaofen 2, LA2329 and LA1777.

The plants sampled for the BC4F2 were field grown. For this generation, seeds were germinated on moist filter paper in an incubator $\left(27^{\circ} \mathrm{C}\right)$. After radicle emergence, seeds were planted in 72-cell trays containing ProMix BX. Six weeks later, seedlings were transplanted into the field at the Horticulture Research Farm, Lexington, KY. Cultural methods for transplant and field production followed those recommended in ID-36 [51].

Other than the BC4F2 generation, all other plants were produced in a greenhouse. Plants were grown in pots filled with ProMix BX (Premier Tech Horticulture, Quakertown, PA, USA) and auto-fertigated every day using a fertilizer solution containing Peter's Professional 5-11-26 (ICL SF USA \& Canada, Dublin, $\mathrm{OH}$ ) plus $\mathrm{CaNO}_{3}$ (Viking Yara, Tampa, FL) to provide $180 \mathrm{ppm}$ of nitrogen. After seedling establishment, plants were maintained by cuttings when needed. Plants were grown under normal daylength 
conditions, during spring, summer, and fall. Throughout this time, the average greenhouse temperature and relative humidity were $24 \pm 2{ }^{\circ} \mathrm{C}$ and $67 \% \mathrm{RH}$, respectively.

All of the analytical procedures relied on hexane leaflet washes. These were obtained by steeping leaflets or pieces of leaflets in a known amount of n-hexane for five minutes. When needed the area of the steeped tissue was determined after extraction by use of digital scanner and image analysis of digitized images with ImageJ [52]. Volume of hexane used, amount of tissue and the manner in which leaflet tissue was collected varied somewhat among generations and those details are provided below in the relevant methods sections on each generation.

Gas chromatography with flame ionization detection (GC-FID) was used to quantify compounds of interest in this research. The column was an RTX-5 column -- 5\% diphenyl 95\% dimethyl polysiloxane, $15 \mathrm{~m}, 0.53-\mathrm{mm}$ ID, $0.5 \mu \mathrm{m}$ (Restek Corporation, Bellefonte, PA, USA). Temperatures were as follows: injector $250^{\circ} \mathrm{C}$, detector $300^{\circ} \mathrm{C}$, oven initial temperature $50^{\circ} \mathrm{C}$ for $1 \mathrm{~min}$, then increasing at $20^{\circ} \mathrm{C} / \mathrm{min}$ to $260^{\circ} \mathrm{C}$. The gas chromatograph used was a Hewlett Packard 5890 Series II. To allow quantitation of compounds detected by GC-FID, a standard curve using tetradecane was constructed over the range of 0 to 100 ppm (0 to $100 \mathrm{ng} / \mu \mathrm{L}$ ). Tetradecane was also used as an external standard as was ginger oil as a source of $\alpha$-zingiberene.

For spectrophotometry, a Thermo Scientific Evolution 60S UV-Visible scanning spectrophotometer was employed. Absorbances of the leaflet washes from the BC4F2 population were determined at a single wavelength $270 \mathrm{~nm}$; all other leaflet washes and samples were scanned from 200 to $500 \mathrm{~nm}$ wavelength at a scanning rate of $1 \mathrm{~nm} \cdot \mathrm{sec}^{-1}$. Results of each scan was stored electronically, with an absorbance value for each wavelength from 200 to $350 \mathrm{~nm}$. In all cases the scans in the region between 350 and $500 \mathrm{~nm}$ had no absorbance relative to the blank, so only absorbance values in the 200 to $350 \mathrm{~nm}$ range were used.

Leaflet washes from the donor and recurrent parents, as well as from the several accessions of $S$. habrochaites were used for qualitative characterization by spectrophotometry. Leaflet washes were prepared by steeping leaflets in hexane ( $\sim 2 \mathrm{ml}$ per leaflet) for few minutes, vortexing, removing leaflets, and then scanning the leaflet washes with the spectrophotometer. Samples were diluted as needed with hexane, to provide clarity in data presentation.

7-epi-zingiberene, 9-hydroxy-zingiberene and 9-hydroxy-10,11-epoxy-zingiberene from the leaflet wash of LA2329-A were isolated by open column chromatography on silica gel as described by Dawood and Snyder [21]. Purity of the isolated compound of interest in each fraction was determined by GC-FID. For qualitative analysis, fractions of the highest purities were scanned with the spectrophotometer in the usual fashion. For quantitative analysis the quantity of 7-epi-zingiberene, 9-hydroxy-zingiberene or 9-hydroxy10,11-epoxy-zingiberene in each silica gel chromatographic fraction was determined by GC-FID and then each isolated fraction was spectrophotometrically scanned. There were 15 fractions of 7-epi-zingberene, 14 fractions of 9-hydroxy-zingiberene and 10 fractions of 9-hydroxy-10,11-epoxy-zingiberene,

To initially evaluate the use of the spectrophotometer for quantitation of 7-epi-zingiberene a widely segregating population, an interspecific BC4F2 population, was evaluated. Leaflet washes from the entire population had previously been evaluated by GCFID to determine concentrations of 7-epi-zingiberene and $\beta$-phellandrene, the main components present in the leaflet washes; oxidized forms of zingiberene were absent. We chose 38 plants from the population that represented a wide range of zingiberene and $\beta$ phellandrene concentrations. Leaflet washes were obtained by taking the middle $1 / 3$ to $1 / 4$ of each of three leaflets from the third or fourth leaf position of each plant, approximately $\sim 10 \mathrm{~cm}^{2}$ foliage, and placing the leaflet tissue in $4.0 \mathrm{ml}$ of $n$-hexane. After vortexing and removing the leaflet tissue, absorbance of the samples at $270 \mathrm{~nm}$ was determined spectrophotometrically and concentrations of 7-epi-zingiberene and $\beta$-phellandrene were determined by GC-FID.

To evaluate the BC3F5 generation, an interspecific population that contained one major compound (7-epi-zingiberene only and no oxidized forms or $\beta$-phellandrene ) in its 
leaflet washes, two sampling procedures (A and B) were used. This was done to explore the accuracy of the spectrophotometric analysis for zingiberene determination, especially with regard to ratio of leaflet tissue to $n$-hexane in the leaflet wash and age of leaflet tissue. The same twenty-five genotypes of the BC3F5 interspecific hybrid population were used for each procedure. In procedure A, three small, entire leaflets were taken (average leaflet area $=28.0 \mathrm{~cm}^{2}$, range $=21.7-37.3 \mathrm{~cm}^{2}$ ), and the leaflets of each genotype were placed in a $20 \mathrm{~mL}$ disposable scintillation vial containing $4 \mathrm{~mL}$ of $n$-hexane. With procedure $\mathrm{B}$ the middle parts (center $1 / 3$ to $1 / 4$ of the leaflet) from each of three leaflets (average $=14.4 \mathrm{~cm}^{2}$, range $=9.5-20.5 .3 \mathrm{~cm}^{2}$ ) were taken and placed in a $20 \mathrm{~mL}$ disposable scintillation vial containing $4 \mathrm{~mL}$ of $n$-hexane. For both procedures, vials were vortexed, and then all samples were scanned with the spectrophotometer and 7-epi-zingiberene concentrations were determined by GC-FID.

The BC5F1 interspecific hybrid population had low 7-epi-zingiberene concentrations, variable, low $\beta$-phellandrene concentrations and produced no oxidized forms of zingiberene as determined by GC-FID. Ten $\mathrm{cm}^{2}$ of foliage from the third and fourth leaf position of each of 10 plants was taken in duplicate (10 plants $\times 2$ replications) by use of a leaf punch. Leaflet washes were prepared in the usual fashion with $n$-hexane and then evaluated by spectrophotometer and by GC-FID.

The $\mathrm{BC} 2 \mathrm{~F} 3$ generation was chosen because it was segregating for the presence and abundance of 7-epi-zingiberene, and its two oxidized forms. Based on GC-FID analysis, 31 plants were chosen for this phase of the research. Twenty-eight of the plants were producing zingiberene and its oxidized forms in their trichome secretions and three plants were producing zingiberene only. Leaflet tissue was obtained in a fashion identical to that used for the BC4F2. Leaflet tissue (average $14.5 \pm 0.44$, range $9.1-29.4 \mathrm{~cm}$ ) was placed into $20 \mathrm{ml}$ scintillation vials, $5 \mathrm{ml}$ of hexane was added and then samples were vortexed. Subsequently, because of high absorbance values of undiluted samples, the samples were diluted 1:5 with hexane prior to spectrophotometric and GC-FID analysis. All samples were duplicated.

Statistical analyses were performed via the SAS 9.4 statistics package (SAS Institute Inc., 2016) and Excel (Microsoft 365, 2019). Average spectra were obtained by determining the mean absorbance at each wavelength from 200 to $350 \mathrm{~nm}$ for each generation or in the case of the BC3F5, for each sampling procedure. Spectrophotometric wavelength regions of interest then were identified visually from the plots of average spectra. Once a region was identified, the maximum absorption value and its wavelength in the region were identified for each genotype and replication by use of the Means Procedure in SAS. Once the wavelength of maximum absorbance was identified for each sample, the mean, maximum, minimum and standard error values of the identified wavelengths were then calculated in the usual fashion.

Simple regression analysis was used to investigate the association between the absorbance at a single wavelength and the concentration of 7-epi-zingiberene or other compounds of interest. In some cases, multiple wavelengths were evaluated as a means to improve predictions of zingiberene from UV absorbance values. This was accomplished by use of stepwise regression with forward selection in SAS using the GC-FID area units for the target compound(s) as the dependent variable, and the absorbance recorded for each wavelength in the 200-350 $\mathrm{nm}$ region of the absorbance spectrum as independent variables. Only variables significant at $\mathrm{P} \leq 0.01(\mathrm{SLE}=0.01$ ) were allowed entry into the regression, thus minimizing the number independent variables in the models. After these significant wavelengths were identified, they were used as independent variables to calculate a predicted value for compounds of interest from the spectrophotometric absorbance values for each sample. In certain cases, the amount of compound per $\mathrm{cm}^{2}$ of leaflet area was calculated from the data.

\section{Results}




\begin{tabular}{|c|c|c|c|c|}
\hline \multirow[b]{3}{*}{ Generation } & \multirow[b]{3}{*}{ Compound } & & \multicolumn{2}{|c|}{ Range } \\
\hline & & Mean & Low & High \\
\hline & & \multicolumn{3}{|c|}{----- $\mu \mathrm{g} / \mathrm{cm}^{2}$ of foliage---- } \\
\hline $\mathrm{BC} 3 \mathrm{~F} 5 /$ procedure A & 7-epi-zingiberene & 4.3 & 0.4 & 4.3 \\
\hline $\mathrm{BC} 3 \mathrm{~F} 5 /$ procedure A & $\beta$-Phellandrene & 0 & 0.0 & 0.0 \\
\hline $\mathrm{BC} 3 \mathrm{~F} 5 /$ procedure $\mathrm{B}$ & 7-epi-zingiberene & 2.1 & 0.3 & 6.9 \\
\hline BC3F5/ procedure B & $\beta$-Phellandrene & 0 & 0.0 & 0.0 \\
\hline $\mathrm{BC} 4 \mathrm{~F} 2$ & 7-epi-zingiberene & 3.6 & 0.0 & 17.7 \\
\hline $\mathrm{BC} 4 \mathrm{~F} 2$ & $\beta$-Phellandrene & 5 & 0.0 & 11.6 \\
\hline BC5F1 & 7-epi-zingiberene & 1.4 & 0.1 & 2.9 \\
\hline BC5F1 & $\beta$-Phellandrene & 0.9 & 0.2 & 1.7 \\
\hline $\mathrm{BC} 2 \mathrm{~F} 3$ & 7-epi-zingiberene & 4.7 & 1.0 & 36.6 \\
\hline \multirow[t]{2}{*}{ BC2F3 } & $\beta$-Phellandrene & 0.7 & 0.0 & 8.5 \\
\hline & 9-hydroxy- & & & \\
\hline $\mathrm{BC} 2 \mathrm{~F} 3$ & zingiberene & 2.4 & 0.0 & 9.5 \\
\hline $\mathrm{BC} 2 \mathrm{~F} 3$ & $\begin{array}{l}\text { 9-hydroxy,10,11- } \\
\text { epoxy-zingiberene }\end{array}$ & 1.3 & 0.0 & 3.9 \\
\hline $\mathrm{BC} 2 \mathrm{~F} 3$ & Total zingiberenoids & 8.5 & 2.1 & 36.6 \\
\hline
\end{tabular}

Relationship between 7-epi-zingiberene content and absorbance at $270 \mathrm{~nm}$ in a BC4F2 generation

The ranges of concentrations of zingiberene and $\beta$-phellandrene for the BC4F2 plants used are listed in Table 1. This generation did not produce any oxidized form of zingiberene. For the leaflet washes obtained from the 38 individual BC2F4 plants there was a strong association $\left(\mathrm{R}^{2}=0.92\right)$ between 7 -epi-zingiberene content as measured by GCFID and absorbance at $270 \mathrm{~nm}$ (Figure 2). The two plants having the highest concentration of 7-epi-zingiberene in their leaflet washes as measured by GC-FID were readily distinguished by their high absorbance values. Regression analysis indicated that slope $(\mathrm{t}=25.09, \mathrm{P}<0.001)$ and interestingly, the intercept $(\mathrm{t}=15.98, \mathrm{P}<0.0001)$ were highly significant. The latter is a strong evidence that the predicted intercept was not equal to 0 , meaning that the predicted regression equation did not pass through the origin. Because of this, we examined in more detail the absorbance values for samples that had no detectable zingiberene as determined by GC-FID, i.e., those samples that displayed scatter at the origin (Figure 2). For those samples that contained little or no zingiberene $(n=19)$, absorbance at $270 \mathrm{~nm}$ ranged from 0.158 to 0.534 and averaged 0.367 absorbance units, so even in the absence of zingiberene, there was considerable absorbance detected at $270 \mathrm{~nm}$ in these 19 samples that was unrelated to zingiberene content. Thus, the presence of compounds other than 7-epi-zingiberene in the leaflet washes must have contributed to absorbance at $270 \mathrm{~nm}$. Many of these leaflet washes, nearly all of them, contained $\beta$ phellandrene as a major component as determined by GC-FID. However, it is unlikely that $\beta$-phellandrene contributed to absorbance at $270 \mathrm{~nm}$ because this compound has negligible absorbance at $270 \mathrm{~nm}$ [45].

Table 1. Average 7-epi-zingiberene and $\beta$-phellandrene contents $\left(\mu \mathrm{g} / \mathrm{cm}^{2}\right.$ of foliage) for BC3F5, $\mathrm{BC} 4 \mathrm{~F} 2, \mathrm{BC} 5 \mathrm{~F} 1$ and $\mathrm{BC} 2 \mathrm{~F} 3$ generations and 9-hydroxy-zingiberene, 9-hydroxyzingiberene and total zingiberenoid contents for the $\mathrm{BC} 2 \mathrm{~F} 3$ generation of interspecific hybrid tomatoes evaluated. Two sampling procedures were used for the BC3F5 population (see text). 


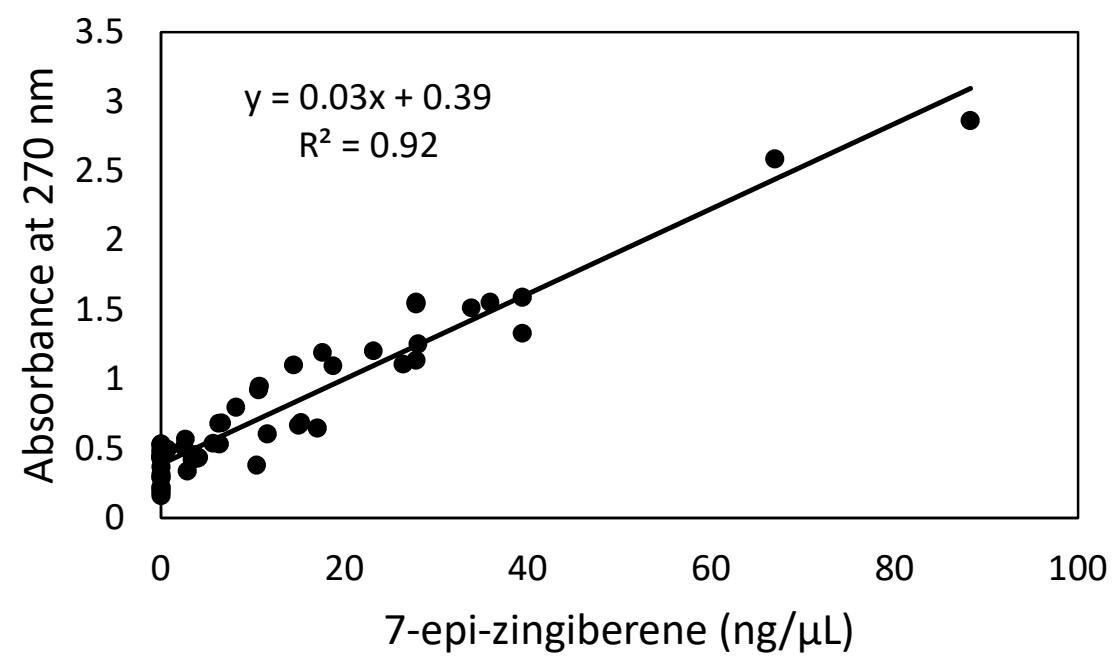

Figure 2. Association between absorbance at $270 \mathrm{~nm}$ and 7-epi-zingiberene concentration $(\mathrm{ng} / \mu \mathrm{L})$ measured by GC-FID of $n$-hexane leaflet washes from BC4F2 interspecific hybrid plants, $\mathrm{n}=38$.

Based on these results the method appeared promising, especially for identification of those few individuals occurring in a segregating population that have exceptionally high zingiberene concentrations [46]. These individuals were clearly differentiated by measuring absorbance at 270, the wavelength used by Freitas, Maluf, das Graças Cardoso, Gomes and Bearzotti [46] to identify in a segregating population those few individuals having very high zingiberene concentrations. However, the selection or identification of plants having intermediate to low, or zero concentration of 7-epi-zingiberene as measured by UV absorbance at $270 \mathrm{~nm}$ would be considerably less reliable. A breeder might want to select for presence of lower concentrations of zingiberene, especially if lower concentrations conferred similar levels of arthropod resistance, or if high zingiberene concentration was related to negative characters such as reduced yield. Those who study plantinsect interactions in populations segregating for zingiberene also would likely want to evaluate plants having a wide range of zingiberene concentrations and would certainly want to evaluate plants having intermediate, low and zero levels of zingiberene. Based on our results, measurement of absorbance at 270 would not reliably identify these concentrations of zingiberene. We were also curious about the choice of $270 \mathrm{~nm}$ as the wavelength for evaluating zingiberene content because the predicted $\lambda$ max of 7-epi-zingiberene is 263-264 nm [53]. Additionally, our initial attempts at evaluating 7-epi-zingiberene concentration by use of absorbance at $270 \mathrm{~nm}$ in a complex $\mathrm{BC} 2$ generation that produced an array of oxidized sesquiterpenoids, rather than a single sesquiterpene, by measurement of absorbance at 270 failed (data not shown). On the other hand, an analytical method based on measurement absorbance of a leaflet wash is a much more rapid and simpler than a chromatography-based analytical methods such as GC-FID or high-performance liquid chromatography. And, spectrophotometers are considerably less expensive than gas or liquid chromatographs, so a spectrophotometric method is likely accessible to more researchers and breeders. Consequently, for all of the above reasons we decided to critically evaluate the use of spectrophotometry for estimation of 7-epi-zingiberene in segregating, interspecific tomato populations.

\subsection{UV absorbance of tomato terpenoids -- qualitative aspects}

\subsubsection{Absorbance spectra of leaflet washes}

The absorbance spectra of hexane leaflet washes for the S. habrochaites accession that produces 7-epi-zingiberene only -- LA2329-B and for those that produce 7-epi- 
zingiberene, 9-hydroxy-zingiberene and 9-hydroxy-10,11-epoxy-zingiberene, LA2329-A, PI127826, and LA2167 [21] had similar broad absorption peaks ( $\lambda$ max) at $264 \pm 0 \mathrm{~nm}$ (Figure 3). LA1777 is not known to produce 7-epi-zingiberene or its derivatives but does produce other sesquiterpenoids, mainly high concentrations of sesquiterpenoid acids derived from santalene and bergamotene [48]. The leaflet wash from LA1777 had a UV absorbance spectrum distinct from those of the zingiberene producing wild accessions, having a $\lambda \max$ at $218 \mathrm{~nm}$. The absorbance spectrum for the hexane leaflet wash obtained from Zaofen 2, the cultivated tomato used as recurrent parent was distinct from the those obtained from the $S$. habrochaites accessions, showing a broad $\lambda$ max centered at $232-233 \mathrm{~nm}$. The latter is likely associated with the presence of $\beta$-phellandrene a monoterpene that is commonly produced by tomato cultivars and has an $\lambda$ max of $232-233 \mathrm{~nm}$ $[45,54]$. Thus. the absorption spectra of hexane leaflet washes from those plants that produce zingiberene and its derivatives were qualitatively very similar to each other and distinct from spectra of washes obtained from plants that do not produce zingiberene and its derivatives. These results are consistent with the idea that zingiberene and its derivatives may be responsible for the $\lambda \max$ at $264 \mathrm{~nm}$.

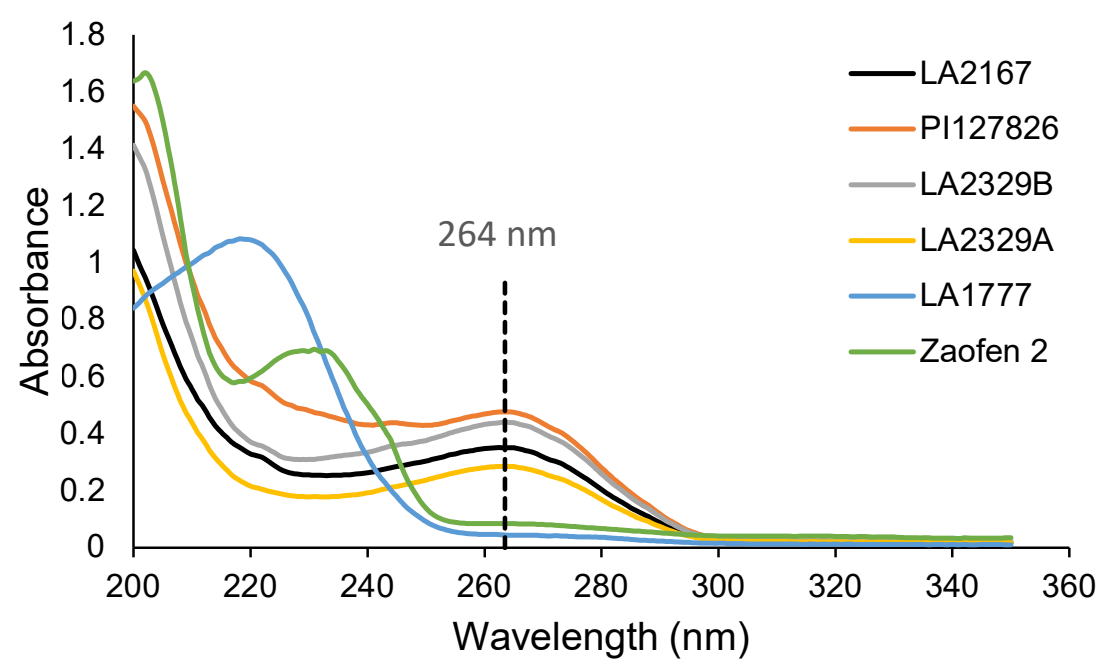

Figure 3. Examples of UV absorbance spectra for hexane leaflet washes from five accessions of Solanum habrochaites and one tomato (S. lycopersicum) variety, Zaofen 2 . The vertical dashed line identifies $264 \mathrm{~nm}$, the $\lambda \max$ in the 250-290 $\mathrm{nm}$ region of the spectra for accessions that produce 7epi-zingiberene and its oxidized forms.

\subsubsection{Absorbance spectra of isolated sesquiterpenoids (zingiberenoids)}

We successfully separated 7-epi-zingberene, 9-hydroxy-zingiberene and 9-hydroxy10,11-epoxy-zingiberene by silica gel chromatography. The purity of the isolated zingiberene was high, about $88 \%$ as judged by GC-FID. Isolated alcohol and epoxy alcohol were less pure, averaging about $49 \%$ and $43 \%$, respectively and based on GC-FID, were each the predominate component of their respective isolated fractions. Importantly, these isolated fractions were not cross contaminated. Non-target compounds were numerous in the fractions that contained 9-hydroxy-zingiberene or 9-hydroxy-10,11-epoxy-zingiberene and individually the non-target compounds were less than $5 \%$ of the total detected by GCFID in a fraction. Scans of isolated fractions containing 7-epi-zingberene, 9-hydroxy-zingiberene or 9-hydroxy-10,11-epoxy-zingiberene were nearly identical qualitatively, displaying a broad absorption peak at $264 \mathrm{~nm}$ (Figure 4). The actual average $\lambda$ max values for the fractions of isolated compounds were $264 \pm 0.3$ for each compound. This indicates that the three zingiberene-related compounds likely have qualitatively similar absorbance spectra, especially with regard to a $\lambda \max$ of $264 \mathrm{~nm}$. Furthermore, the absorption spectra 
in the 240-290 $\mathrm{nm}$ region for the isolated compounds are very similar to those for the crude leaflet washes for accessions that produced zingiberene and its oxidized forms (Figure 3). In these scans of isolated compounds, absorbance at 270, the wavelength used by Freitas, Maluf, das Graças Cardoso, Gomes and Bearzotti [46] for selection of zingiberene in interspecific population is about $90 \%$ of the absorbance at $264 \mathrm{~nm}$.

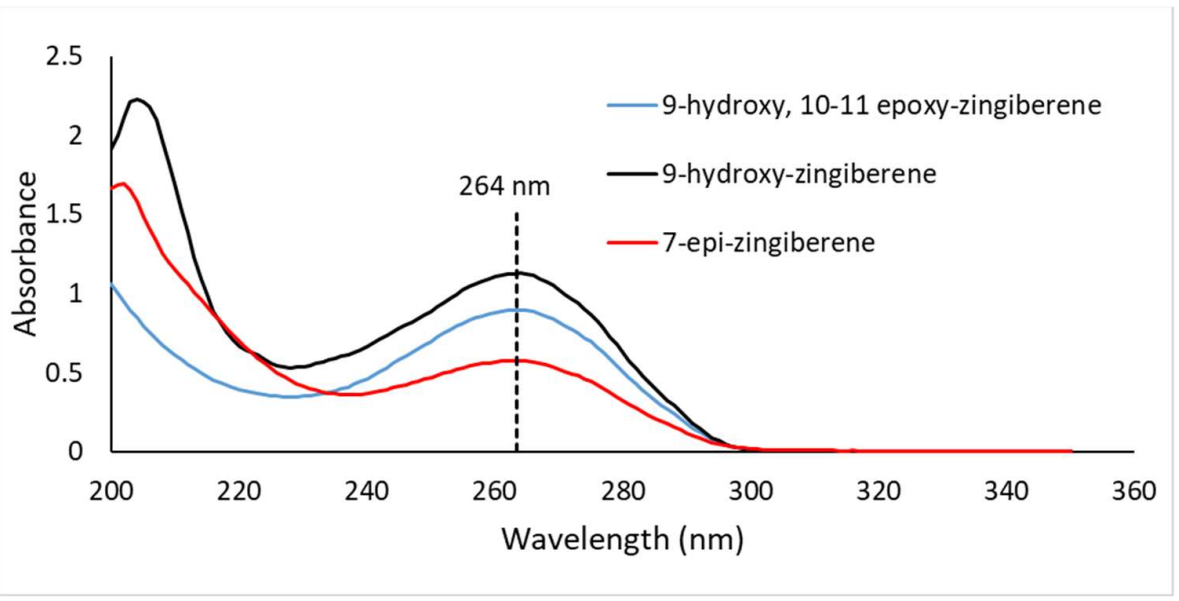

Figure 4. Example absorbance spectra for 7-epi-zingiberene, 9-hydroxy-zingiberene and 9-hydroxy-10, 11-epoxy zingiberene isolated by silica gel chromatography. The vertical dashed line identifies $264 \mathrm{~nm}$, the $\lambda \max$ in the $250-290 \mathrm{~nm}$ region for these compounds.

\subsubsection{Summary and implications of qualitative spectrophotometry}

7-Epi-zingiberene has a $\lambda$ max of 264 as do its oxidized forms. The absorbance related to these compounds is readily distinguished in crude leaflet washes as well as in isolated fractions of each compound. Thus, it is likely the presence of the oxidized forms would interfere with quantitation of 7-epi-zingiberene by spectrophotometry when they are present. Based on the finding of similar $\lambda$ max values for isolated fractions and leaflet wash samples from accessions, it is likely that the presence of a broad peak at $264 \mathrm{~nm}$ in the leaflet washes is associated with the presence of zingiberene or its oxidized forms. Likewise, the presence of $\beta$-phellandrene in the leaflet wash of Zaofen 2 is likely associated with the presence of an absorbance peak at 233-234 nm. However, the simple presence of absorbance in the $264 \mathrm{~nm}$ region, without a peak, such as that observed for the leaflet wash from Zaofen 2 (Figure 3) does not indicate the presence of zingiberene or its oxidized forms and is likely due to the presence of other compounds that, if present in breeding or segregating populations, could complicate quantitation of 7-epi-zingiberene and its oxidized forms by spectrophotometric methods.

\subsection{UV absorbance of tomato terpenoids -- quantitative aspects}

3.3.1. Absorbance vs. concentration of 7-epi-zingiberene, 9-hydroxy-zingiberene and 9hydroxy, 10, 11-epoxy-zingiberene

Regressions between GC-FID detector response and absorbance at $264 \mathrm{~nm}$, the $\lambda$ max for these compounds were generated for the isolated fractions of 7-epi-zingiberene, 9-hydroxy-zingiberene and 9-hydroxy-10,11-epoxy-zingiberene obtained by silica gel chromatography (Figure 5). The resulting regression equations were similar, but not identical. (Table 2). $\mathrm{R}^{2}$ values were high for all three compounds. Slopes for 9-hydroxy-zingiberene was somewhat lower that that obtained for the other two compounds. For two of the compounds, 7-epi-zingiberene and 9-hydroxy-10,11-epoxy-zingiberene, intercepts did not differ significantly from 0 , but the intercept for 9-hydroxy-zingiberene was greater than 0 , likely indicating the presence of compounds other than 9-hydroxy-zingiberene contributed to absorption at $264 \mathrm{~nm}$ in these isolated fractions. The similar slopes among these 
regressions support the idea that the molar absorptivity values for the three related compounds are likely very similar to each other. However, because the isolated compounds, especially the 9-hydroxy-zingiberene and 9-hydroxy-10,11-epoxy-zingiberene were not of high purity, and because of the possibility of different response of the GC detector to these compounds prevents a strong conclusion regarding whether or not the molar absorptivity values are exactly identical. Regression of absorbance at $270 \mathrm{~nm}$ on GC detector response was also accomplished for the isolated fractions of each compound. Results were very similar to those obtained for regression of absorbance at $264 \mathrm{~nm}$, except that the slopes for former were about $10 \%$ lower for the former, compared to the latter.

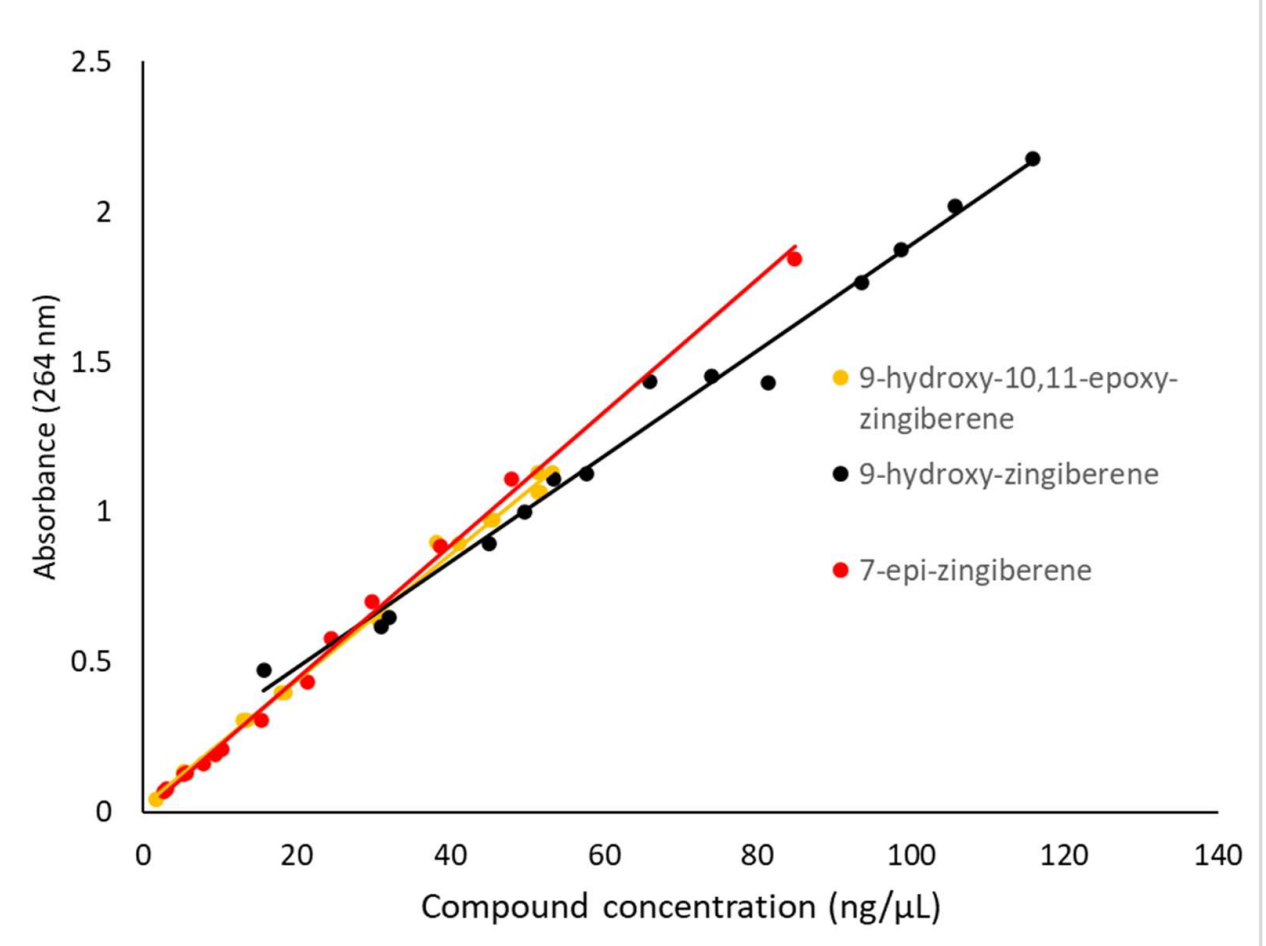

Figure 5. Linear relationships between absorbance measured at $264 \mathrm{~nm}$ and compound concentration $(\mathrm{ng} / \mu \mathrm{L})$ for fractions of 7 -epi-zingiberene and its two oxidized forms isolated by silica gel chromatography.

Table 2. Results of regression of absorbance at $264 \mathrm{~nm}$ on GC-FID detector response for fractions of 7-epi-zingiberene, 9hydroxy-zingiberene and 9-hydroxy, 10,11 epoxy-zingiberene isolated by silica gel chromatography.

\begin{tabular}{|c|c|c|c|c|c|c|c|c|}
\hline \multirow{2}{*}{$\begin{array}{l}\text { Isolated com- } \\
\text { pound }\end{array}$} & \multirow[b]{2}{*}{$\mathbf{N}$} & \multirow[b]{2}{*}{$\mathbf{R}^{2}$} & \multirow[b]{2}{*}{ Intercept } & \multicolumn{2}{|c|}{$\begin{array}{c}\text { 95\% Confidence } \\
\text { limits }\end{array}$} & \multirow[b]{2}{*}{ Slope } & \multicolumn{2}{|c|}{$\begin{array}{c}\text { 95\% Confidence } \\
\text { limits } \\
\end{array}$} \\
\hline & & & & lower & upper & & lower & upper \\
\hline 7-epi-zingiberene & 14 & 0.997 & 0.000 & -0.025 & 0.025 & 0.022 & 0.021 & 0.023 \\
\hline $\begin{array}{l}\text { 9-hydroxy- } \\
\text { zingiberene }\end{array}$ & 14 & 0.986 & 0.130 & 0.035 & 0.225 & 0.018 & 0.016 & 0.019 \\
\hline $\begin{array}{l}\text { 9-hydroxy-10,11- } \\
\text { epoxy-zingiberene }\end{array}$ & 18 & 0.996 & 0.020 & -0.003 & 0.044 & 0.021 & 0.020 & 0.022 \\
\hline
\end{tabular}


3.3.2. Relationship between absorbance values at several wavelengths and zingiberene concentrations in a BC3F5 generation

Evaluation of zingiberene in this population presents a relatively simple case, because all plants produced 7-epi-zingiberene only and $\beta$-phellandrene was not detected by GC-FID in any of the samples. (Table 1). Average absorbance spectra from 200-350 $\mathrm{nm}$ for the A and B samples were very similar in shape (Figure 6). However, the average absorbance values were higher for the A samples, reflecting the relatively higher ratios of leaflet area:extractant in the A samples, compared to B (Table 1).

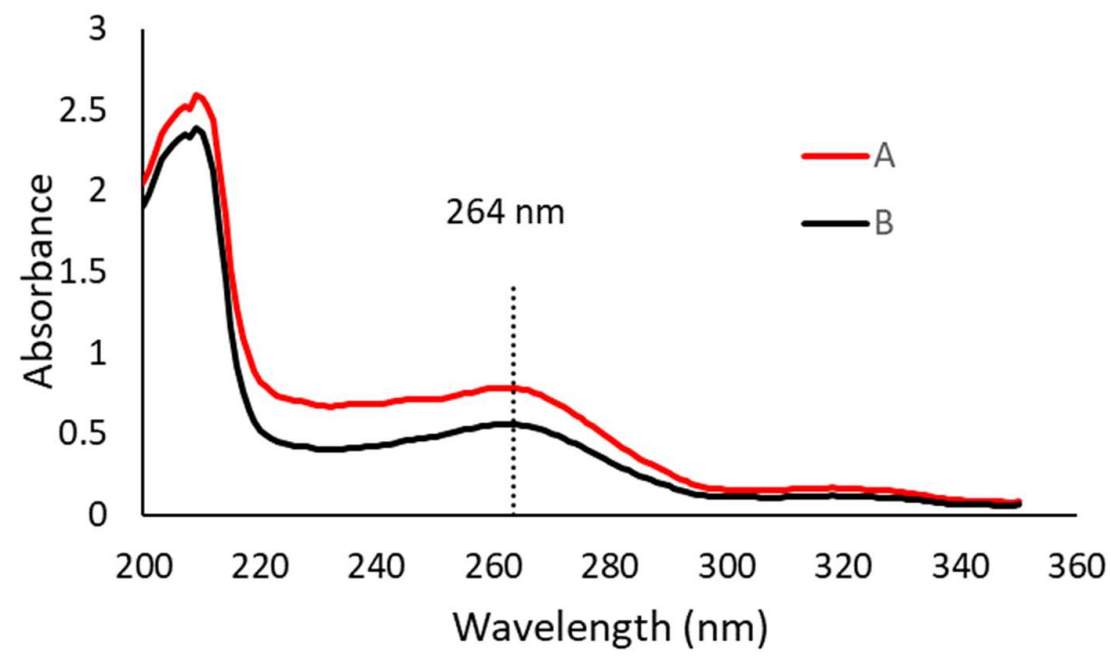

Figure 6. UV absorbance spectra for hexane leaflet washes of BC3F5 plants obtained by two methods, A and B (see text). The vertical dashed line identifies $264 \mathrm{~nm}$, the $\lambda$ max for 7-epi-zingiberene in the $250-290 \mathrm{~nm}$ region.

Average absorbance maximum in the $250-290 \mathrm{~nm}$ region was $262 \pm 0.4 \mathrm{~nm}$ for the A samples and $262 \pm 0.3$ for the B samples, indicating a slight shift the absorbance maximum, compared to that obtained for isolated 7-epi-zingiberene (Figure 4) However, the modal $\lambda$ max value for the A and B samples was 263 or 264 for 14 of 25 of the A samples and was 15 out of 25 of the B samples. So, the shift was only present in a minority of the A and B samples.

When absorbance at $264 \mathrm{~nm}$ was regressed on 7-epi-zingiberene content for the two sets of samples there were apparent differences, mainly in the intercepts (Figure 7, Table 3). Compared to the regression for the B samples, the regression for the A samples had a considerably lower $\mathrm{R}^{2}$ value, indicating greater scatter, and also had a higher intercept, likely indicating the greater influence of interfering compounds, compounds other than 7-epi-zingiberene, in these more concentrated samples obtained from younger leaves; slopes for the regressions were very similar. 


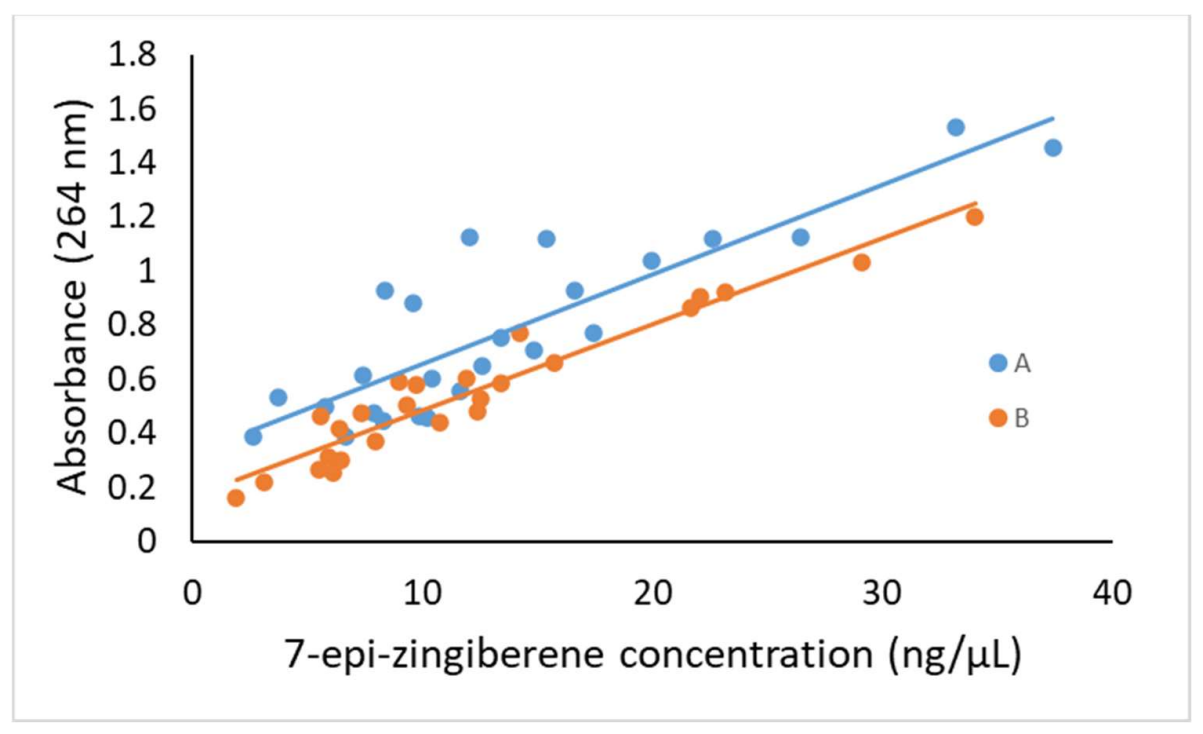

Figure 7. Relationship between absorbance at $264 \mathrm{~nm}$ and 7-epi-zingiberene contents of BC3F5 plants sampled by two methods, A and B (see text).

Table 3. Results of regression of absorbance at the indicated wavelength on 7-epi-zingiberene content (ng/ $\mu \mathrm{L})$ for hexane leaflet washes from BC3F5 plants sampled by two sampling methods, A and B (see text).

\begin{tabular}{|c|c|c|c|c|c|c|c|c|}
\hline \multirow{2}{*}{$\begin{array}{c}\text { Sampling } \\
\text { method }\end{array}$} & \multirow{2}{*}{$\begin{array}{c}\text { Y-variable } \\
(\mathrm{nm})\end{array}$} & \multirow[b]{2}{*}{$\mathbf{R}^{2}$} & \multirow[b]{2}{*}{ Intercept } & \multicolumn{2}{|c|}{$\begin{array}{c}\text { 95\% Confidence } \\
\text { limits }\end{array}$} & \multirow[b]{2}{*}{ Slope } & \multicolumn{2}{|c|}{$\begin{array}{c}95 \% \text { Confidence } \\
\text { limits }\end{array}$} \\
\hline & & & & Lower & Upper & & Lower & Upper \\
\hline A & 264 & 0.75 & 0.32 & 0.19 & 0.46 & 0.033 & 0.025 & 0.041 \\
\hline B & 264 & 0.92 & 0.17 & 0.11 & 0.23 & 0.032 & 0.028 & 0.036 \\
\hline A & 270 & 0.80 & 0.25 & 0.17 & 0.34 & 0.030 & 0.023 & 0.037 \\
\hline B & 270 & 0.94 & 0.13 & 0.09 & 0.17 & 0.028 & 0.025 & 0.032 \\
\hline
\end{tabular}

Because previous work $[23,46]$ relied on measuring absorbance at $270 \mathrm{~nm}$ to estimate zingiberene content, we also determined relationship between absorbance at 270 and zingiberene content for the BC3F5 A and B samples (Table 3). The results were similar to results for regressions of absorbance at $264 \mathrm{~nm}$, with very similar $\mathrm{R}^{2}$ values and intercepts, and estimated slopes that were reduced about $10 \%$, but statistically indistinguishable from those obtained with regression at $264 \mathrm{~nm}$, agreeing with our previous results that indicated for isolated 7-epi-zingiberene absorbance at $270 \mathrm{~nm}$ was about $90 \%$ of the absorbance at $264 \mathrm{~nm}$.

The presence of the subtle shift in absorbance maximum in the BC3F5 leaflet washes to a value lower than that observed for isolated 7-epi-zingiberene and the presence of nonzero intercepts in the regression analyses suggest that absorbance values in the $264 \mathrm{~nm}$ region were affected by the presence of compounds other than 7-epi-zingiberene. And the greater intercept associated with the A samples suggested that this effect of non-target compounds was greater in the A samples, compared to the B samples. Close inspection of the average absorbance spectra for the A and B samples provides additional evidence for differences in these average absorbance spectra: for the A samples, the ratio between absorbances at 230 and 264 was 0.88 , and for the B samples, this ratio was considerably less, 
0.72. The higher ratio for the A samples compared to the B samples also corresponded with a higher intercept and reduced $\mathrm{R}^{2}$ values for the A samples, compared to the B samples in the regressions.

Because of the difference of the $230 \mathrm{~nm}: 264 \mathrm{~nm}$ absorbance ratios for the A and B samples, we performed stepwise regression between 7-epi-zingiberene contents based on GC-FID as the dependent variable and absorbances from 200 to 360 as independent variables for the A and B samples separately, aiming to determine if inclusion of absorbances at two or more wavelengths could improve regression results. The best two-variable models for the A samples included wavelengths at 275 and $232 \mathrm{~nm}$. For the B samples the best two variable model included wavelengths at 275 and $221 \mathrm{~nm}$. $\mathrm{R}^{2}$ values were very near 1.0 for both multiple regression models. We then conducted a similar stepwise regression for all samples disregarding their A or B designation and obtained a two variable regression model based on absorbance at 275 with a positive slope, absorbance at 229 with a negative slope, and a very highly significant $R^{2}$ value of 0.97 . The high $R^{2}$ value supports the idea that for these BC3F5 samples, zingiberene content could be predicted by measuring absorbance at two wavelengths, 275 and $229 \mathrm{~nm}$.

Using the results from stepwise regression on the pooled samples we calculated a predicted 7-epi-zingiberene content for each A and B sample based on absorbance at 275 and $229 \mathrm{~nm}$ for comparison to 7-epi-zingiberene content based on GC-FID (Figure 8). The resulting regressions were more similar to each other than when absorbance at a single wavelength was considered (compare Figures 7 and 8), resulting in considerably less scatter, very similar intercepts, and greater similarity between the two sampling methods. Furthermore, the correlation between 7-epi-zingiberene estimated by the two methods was 0.98 over the 25 genotypes.

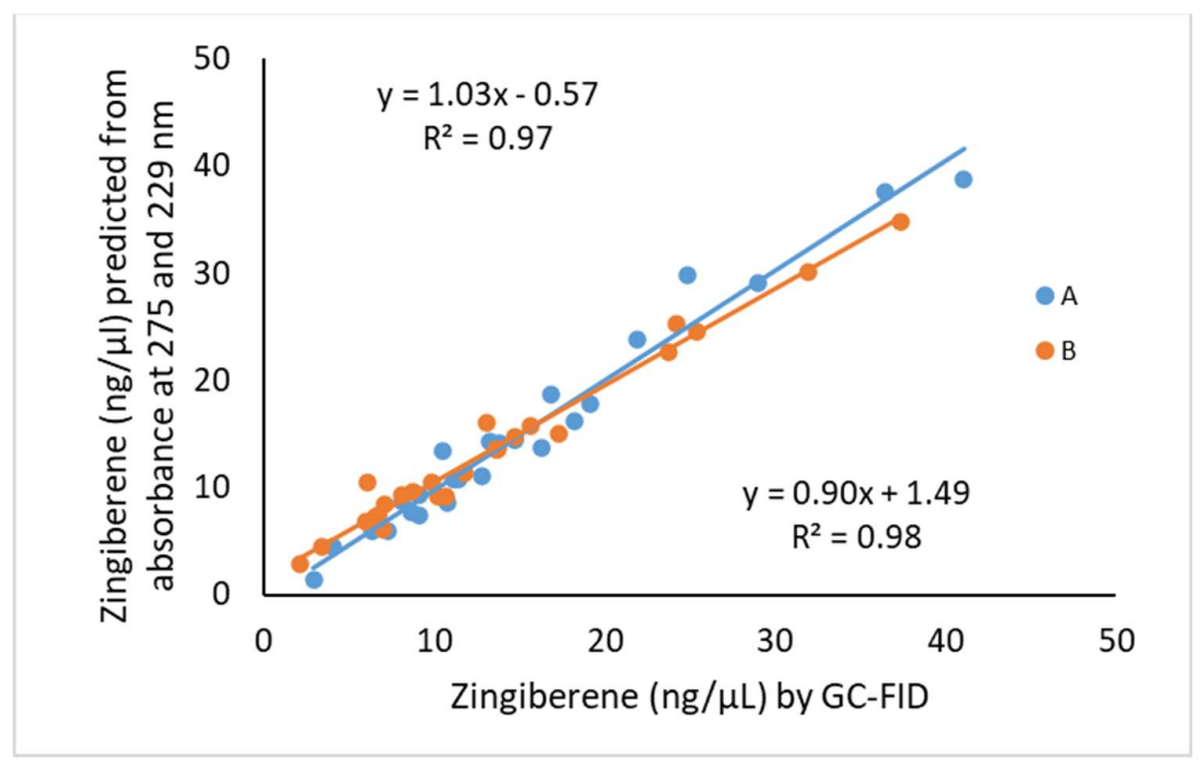

Figure 8. 7-epi-zingiberene contents, predicted from absorbance measured at two wavelengths of leaflet washes from BC3F5 genotypes sampled by two methods, A and B (see text), compared to zingiberene content measured by GC-FID.

3.3.3. Evaluation of a BC5F1 generation having low levels of 7 -epi-zingiberene and $\beta$ phellandrene in its leaflet washes

The terpene composition of leaflet washes of the BC5F1 population presented a somewhat different scenario because this population was an F1 population, where all plants contained $\beta$-phellandrene and 7-epi-zingiberene and average levels of zingiberene were considerably lower than those in the BC3F5 and BC4F2 generations that were previously evaluated (Table 1). Average $\beta$-phellandrene was also lower than that observed in the BC4F2 population. The average absorbance spectrum for this generation 
displayed a significant absorption maximum at $230 \pm 1.5 \mathrm{~nm}$ likely associated with the presence of $\beta$-phellandrene in this population (Figure 9). For individual plants, the wavelength for maximum absorbance in the region ranged from 227-232. Similarly, a subtle, broad peak $(\lambda \max =263 \pm 3.0 \mathrm{~nm})$ likely associated with 7-epi-zingiberene was also present (Figure 9). The $\lambda$ max for individual plants in this region ranged from 260 to $266 \mathrm{~nm}$. Zingiberene was correlated with absorbance at $264 \mathrm{~nm}$ (Figure 10, Table 4) and the relationship between zingiberene and absorbance at 270 was very similar to that at 264 , except, as expected, the slope was reduced by about $10 \%$ (Table 4 ). $\beta$-phellandrene content measured by GC was strongly related to absorbance at $232 \mathrm{~nm}$, (Figure 11, Table 4).

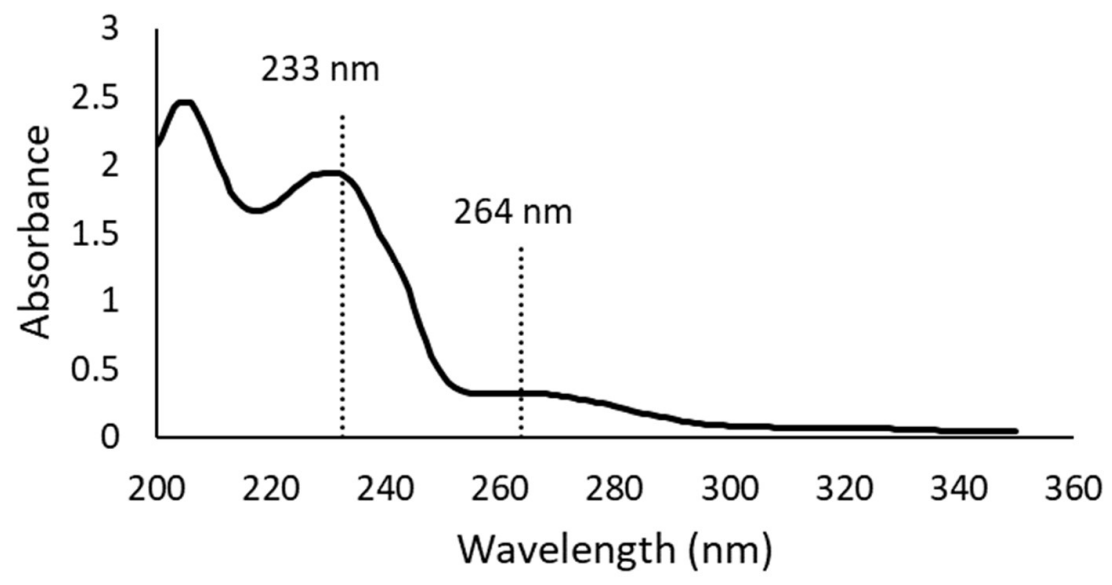

Figure 9. Average absorbance spectrum (200-350 nm) for the leaflet washes obtained from the BC5F1 genotypes. The vertical dashed lines identify 233 and $264 \mathrm{~nm}$, the $\lambda$ max for $\beta$-phellandrene and 7-epi-zingiberene, respectively.

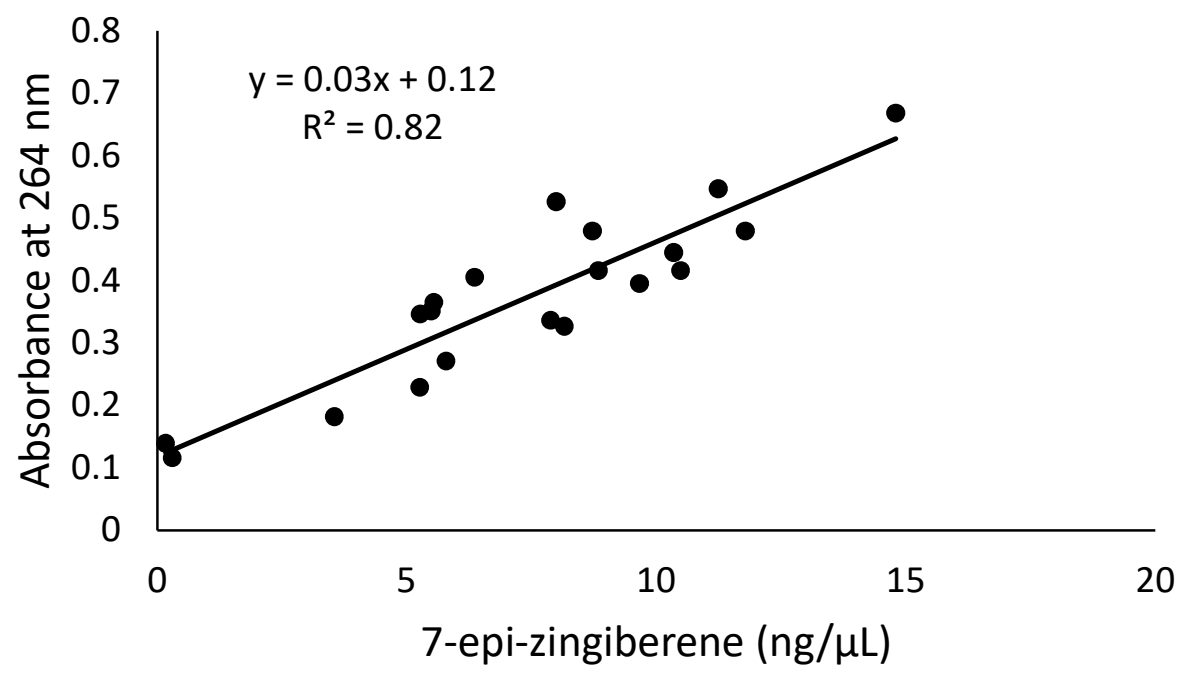

Figure 10. Relationship between absorbance at $264 \mathrm{~nm}$ and 7-epi-zingiberene content determined by GC-FID of leaflet washes obtained from BC5F1 genotypes. 
Table 4. Results of regression analysis between 7-epi-zingiberene content measured by GC-FID and absorbance at 264 or $270 \mathrm{~nm}$ and between $\beta$-phellandrene content measured by GC-FID and absorbance at $233 \mathrm{~nm}$ for BC5F1 leaflet washes.

\begin{tabular}{|c|c|c|c|c|c|c|c|c|}
\hline \multicolumn{2}{|c|}{ Regression variable } & \multirow[b]{2}{*}{$\mathbf{R}^{2}$} & \multirow[b]{2}{*}{ Intercept } & \multicolumn{2}{|c|}{$\begin{array}{c}95 \% \text { Confidence } \\
\text { limit } \\
\end{array}$} & \multirow[b]{2}{*}{ Slope } & \multicolumn{2}{|c|}{$\begin{array}{c}\text { 95\% Confidence } \\
\text { limit } \\
\end{array}$} \\
\hline $\mathrm{Y}(\mathrm{nm})$ & $X(n g / \mu L)$ & & & Lower & Upper & & Lower & Upper \\
\hline 264 & 7-epi-zingiberene & 0.82 & 0.12 & 0.05 & 0.18 & 0.034 & 0.026 & 0.042 \\
\hline 270 & 7-epi-zingiberene & 0.83 & 0.12 & 0.06 & 0.18 & 0.031 & 0.024 & 0.038 \\
\hline 233 & $\beta$-phellandrene & 0.86 & 0.63 & 0.26 & 1.00 & 0.121 & 0.097 & 0.145 \\
\hline
\end{tabular}

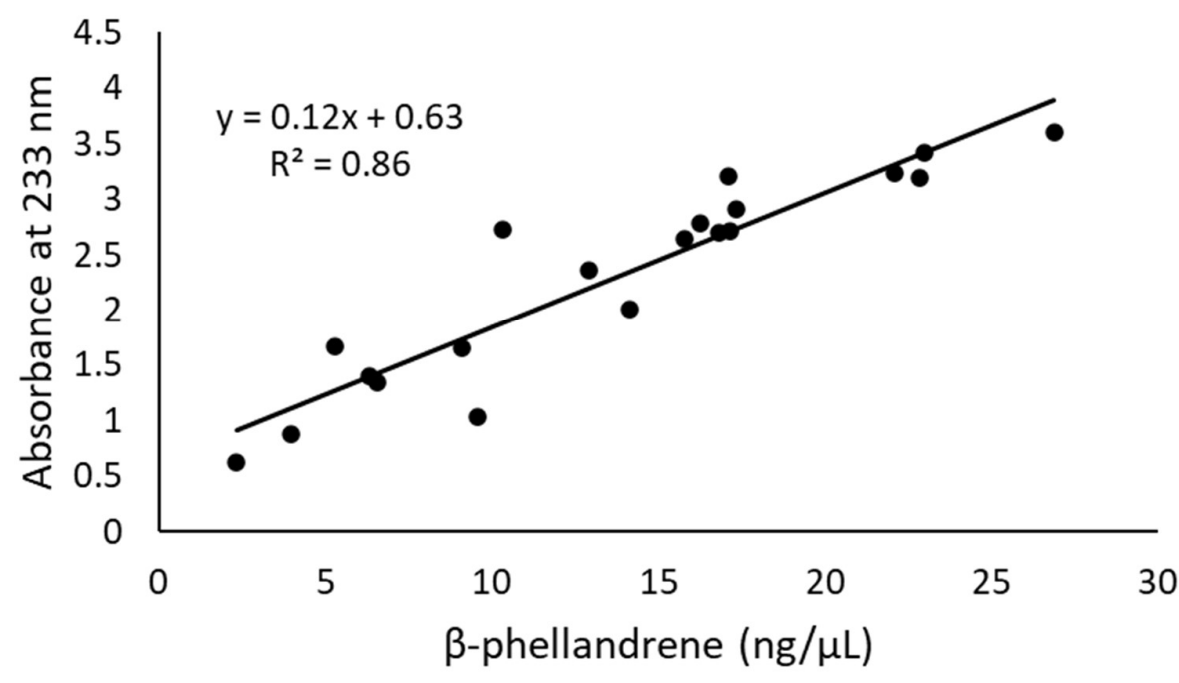

Figure 11. Relationship between absorbance at $233 \mathrm{~nm}$ and $\beta$-phellandrene content determined by GC-FID of leaflet washes obtained from BC5F1 genotypes.

Similar to the approach used for the BC3F5 plants, stepwise regression was used to identify the best multiple wavelengths $(200-350 \mathrm{~nm})$ that were related to $\beta$-phellandrene and zingiberene concentrations. For $\beta$-phellandrene, only a single variable, $231 \mathrm{~nm}$ and no other wavelength met our criteria $(\mathrm{P} \leq 0.01)$ for inclusion in the model (data not included). For zingiberene, absorbance at 265 was selected as the first variable (partial $\mathrm{R}^{2}=$ 0.76 ), and absorbance at 325 (partial $R^{2}=0.16$ ) was selected as the second variable. No other wavelengths met the inclusion criteria so the total $\mathrm{R}^{2}$ was 0.92 . The slope associated with absorbance at 265 was positive and that for 325 was negative.

Based on the identification of absorbances at 265 and $325 \mathrm{~nm}$ as most relevant to zingiberene prediction, we used the results from multiple regression to predict an expected zingiberene content and then compare those results to zingiberene measured by GC-FID, and to absorbance at 264 (Table 5). From these results it can be seen that the rank 
order between predicted and measured zingiberene were identical. This contrasts with ranking based on solely on absorbance at $264 \mathrm{~nm}$ which differed by as many as 2 positions. Thus, spectrophotometric estimation of zingiberene content in this generation was more accurate when based on two wavelengths $(265$ and $325 \mathrm{~nm})$ compared to a single wavelength $(264 \mathrm{~nm})$.

Table 5. Average zingiberene content measured by GC-FID, predicted zingiberene content estimated from absorbance at a single wavelength, $264 \mathrm{~nm}$ and from two wavelengths, 265 and $225 \mathrm{~nm}$ for ten BC5F1 interspecific tomato hybrids. Rank indicates the relative position of the associated mean with 1 indicating largest, and 10, smallest. Change in rank is the difference in rank for the associated mean compared with the ranking of the zingiberene content measured by GC-FID.

\begin{tabular}{|c|c|c|c|c|c|c|c|c|}
\hline \multirow[b]{2}{*}{ Genotype } & \multicolumn{2}{|c|}{ GC-FID } & \multicolumn{3}{|c|}{$\begin{array}{c}\text { Predicted from absorbance at } \\
\text { two wavelengths, } 265 \text { and } 325 \\
\text { nm }\end{array}$} & \multicolumn{3}{|c|}{$\begin{array}{l}\text { Predicted from absorbance at a } \\
\text { single wavelength, } 264 \mathrm{~nm}\end{array}$} \\
\hline & $\begin{array}{l}\text { Average } \\
\mu \mathrm{g} / \mathrm{cm}^{2}\end{array}$ & $\operatorname{Rank}^{1}$ & $\begin{array}{c}\text { Predicted } \\
\mu \mathrm{g} / \mathrm{cm}^{2}\end{array}$ & \multicolumn{2}{|r|}{$\begin{array}{c}\text { Change } \\
\text { in } \\
\text { rank }^{4}\end{array}$} & $\begin{array}{c}\text { Predicted } \\
\mu \mathrm{g} / \mathrm{cm}^{2}\end{array}$ & Rank $^{2}$ & $\begin{array}{c}\text { Change } \\
\text { in } \\
\text { rank }^{4}\end{array}$ \\
\hline $\mathrm{R} 27$ & 2.60 & 1 & 3.07 & 1 & 0 & 2.85 & 1 & 0 \\
\hline R3 & 2.05 & 2 & 2.63 & 2 & 0 & 2.10 & 2 & 0 \\
\hline $\mathrm{R} 23$ & 1.93 & 3 & 1.79 & 3 & 0 & 1.73 & 4 & -1 \\
\hline R113 & 1.77 & 4 & 1.73 & 4 & 0 & 1.99 & 3 & 1 \\
\hline R45 & 1.61 & 5 & 1.66 & 5 & 0 & 1.40 & 6 & -1 \\
\hline R171 & 1.60 & 6 & 1.56 & 6 & 0 & 1.24 & 8 & -2 \\
\hline R199 & 1.16 & 7 & 1.52 & 7 & 0 & 1.50 & 5 & 2 \\
\hline R122 & 1.10 & 8 & 1.19 & 8 & 0 & 1.40 & 7 & 1 \\
\hline R149 & 0.88 & 9 & 0.88 & 9 & 0 & 0.51 & 9 & 0 \\
\hline R55 & 0.05 & 10 & 0.14 & 10 & 0 & 0.06 & 10 & 0 \\
\hline $\mathrm{LSD}_{0.05}$ & 0.77 & & 0.94 & & & 0.07 & & \\
\hline
\end{tabular}

${ }^{1}$ Rank order of average measured $\mu \mathrm{g} / \mathrm{cm}^{2}$

${ }^{2}$ Rank order of average absorbance at $264 \mathrm{~nm}$

${ }^{3}$ Rank order of $\mu \mathrm{g} / \mathrm{cm}^{2}$ predicted from two absorbance values, 265 and $325 \mathrm{~nm}$.

${ }^{4}$ Change in rank relative to 7 -epi-zingiberene $\mu \mathrm{g} / \mathrm{cm}^{2}$ measured by GC-FID

3.3.4. Evaluation of a BC2F3 generation having 7-epi-zingiberene, 9-hydroxy-zingiberene, and 9hydroxy-10,11-epoxy-zingiberene (zingiberenoids) in its leaflet washes

This generation was chosen because it was segregating for the presence and abundance of 7-epi-zingiberene, 9-hydroxy-zingiberene and 9-hydroxy-10,11-epoxy-zingiberene. Table 1 provides range and average content of these compounds in the BC2F3 generation. The 31 plants selected from this generation included three that produced zingiberene only and 28 produced zingiberene and it two oxidized forms. However, for these 28 , the relative abundance of zingiberene-based compounds varied substantially. For these 28 plants 9-hydroxy-10,11-epoxy-zingiberene ranged from 10 to $37 \%$ of zingiberene- 
based compounds, 9-hydroxy-zingiberene ranged from 30 to $50 \%$ and 7-epi-zingiberene ranged from 20 to $54 \%$.

The average of all absorbance spectra obtained for this generation displayed two broad peaks, one with an absorbance maximum at $234 \pm 0.49 \mathrm{~nm}$ and another at $266 \pm 0.20$ $\mathrm{nm}$ (Figure 12). The peak at $234 \mathrm{~nm}$ may be at least partly related to the presence of $\beta$ phellandrene. However, this compound was only detected in 15 samples, and its concentration was low. So, the absorbance present at 234 is likely due to other compounds as well as $\beta$-phellandrene. When absorbance at 264 was regressed against the quantity of 7epi-zingiberene as determined by GC-FID, the $\mathrm{R}^{2}$ value was unsurprisingly rather low, 0.30 , because this regression did not take into account the presence of oxidized forms of zingiberene, which based on our earlier results also have a $\lambda \max$ at $264 \mathrm{~nm}$. When absorbance at $264 \mathrm{~nm}$ was regressed against the sum of zingiberene and its two oxidized forms, the $\mathrm{R}^{2}$ value improved to from 0.31 to 0.53 (Figure 13). The relationship between the two variables displayed considerable scatter that would prevent the using absorbance at this single wavelength to reliably identify those individuals in this generation having the highest concentrations of zingiberene-based compounds.

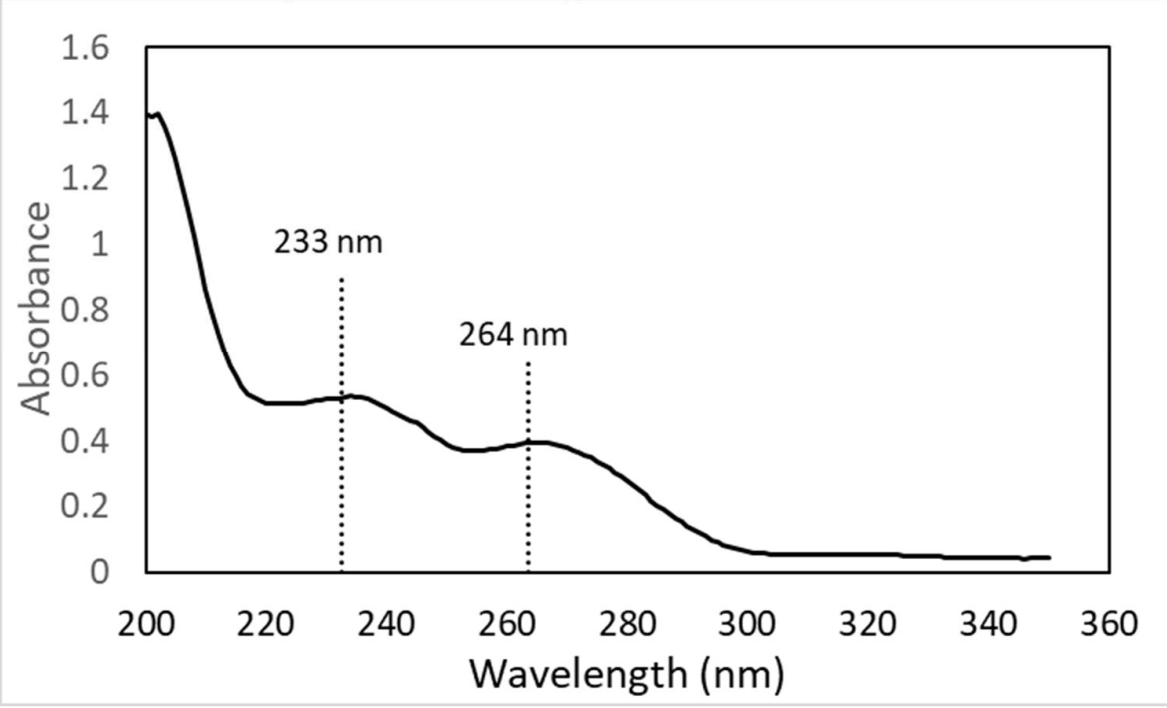

Figure 12. Average absorbance spectrum $(200-350 \mathrm{~nm})$ for leaflet washes obtained from the BC2F3 genotypes. The vertical dashed lines identify 233 and $264 \mathrm{~nm}$, the $\lambda \max$ for $\beta$-phellandrene and 7epi-zingiberene, respectively.

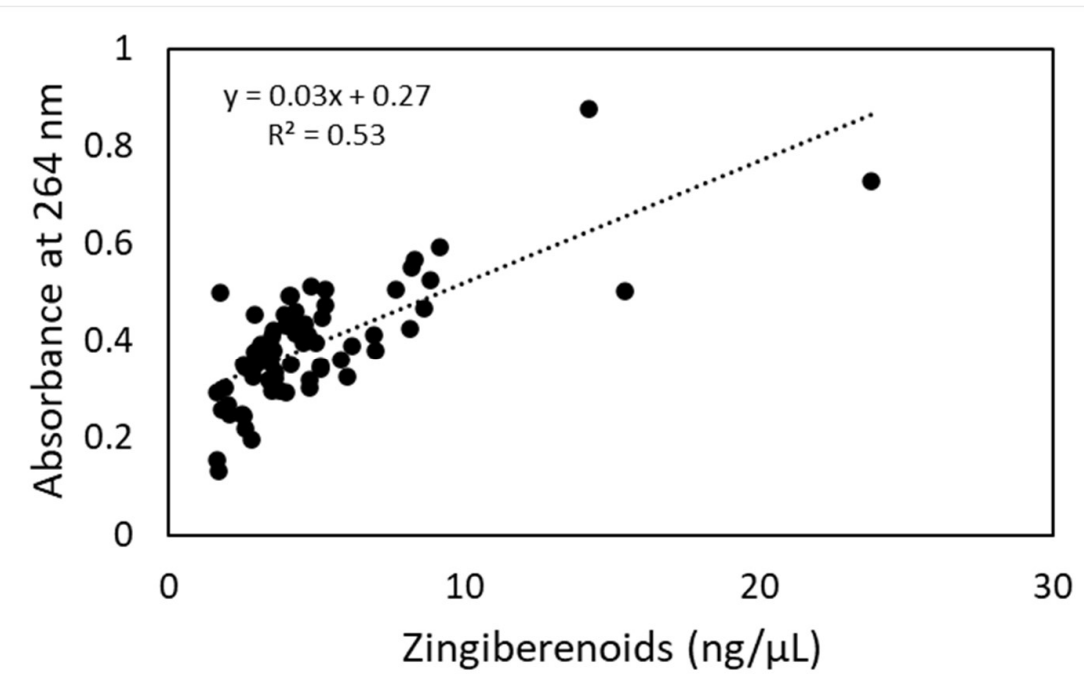


Figure 13. Relationship between absorbance at $264 \mathrm{~nm}$ and the zingiberenoid (7-epi-zingiberene + 9-hydroxy-zingiberene + 9-hydroxy, 10, 11-epoxy-zingiberene) content (ng/ $\mu \mathrm{L}$ ) determined by GCFID of leaflet washes obtained from BC5F1 genotypes.

Using stepwise regression in a fashion similar to that used for other generations, we explored the use absorbance at multiple wavelengths to improve prediction of the quantity of zingiberene related compounds in the BC2F3 generation. Stepwise regression identified three wavelengths: $265 \mathrm{~nm}$ (partial $\mathrm{R}^{2}=0.52$ ); $295 \mathrm{~nm}$ (partial $\mathrm{R}^{2}=0.23$ ) and $253 \mathrm{~nm}$ (partial $\mathrm{R}^{2}=0.10$ ) for a total $\mathrm{R}^{2}$ of 0.85 . The predicted slopes for the latter two wavelengths were negative. Absorbance at these three wavelengths were then used to calculate a predicted quantity of zingiberene compounds, which were then regressed against measured zingiberenoids (Figure 14).

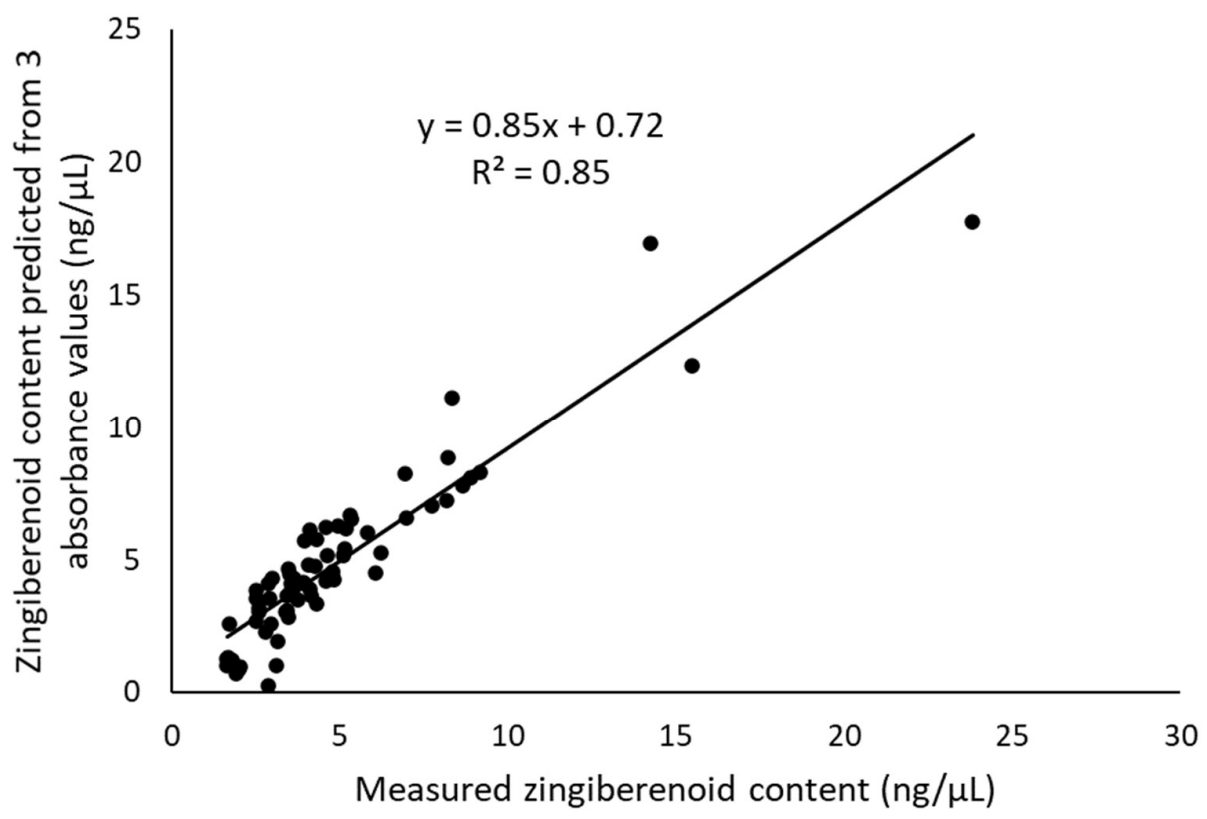

Figure 14. Relationship between zingiberenoid content (7-epi-zingiberene +9 -hydroxy-zingiberene + 9-hydroxy, 10, 11-epoxy-zingiberene) predicted from absorbance measured at two wavelengths and zingiberenoid content measured by GD-FID $(\mathrm{ng} / \mu \mathrm{L})$ of leaflet washes from BC2F3 genotypes.

\section{General discussion and conclusion}

F2 interspecific generations that are segregating for the presence and abundance of 7-epi-ziberene as measured by GC-FID usually have approximately 1 out of 16 individuals having high 7-epi-zingiberene concentrations similar to the donor parent (Snyder, unpublished). In this regard, the 38 BC4F2 individuals that we evaluated for the relationship between absorbance and measured 7-epi-zingiberene content had two such individuals. The absorbances of the leaflet washes at $270 \mathrm{~nm}$ for these two individuals were considerably higher than those for other individuals in the sample (Figure 1). Also, for the other generations evaluated, except the $\mathrm{BC} 2 \mathrm{~F} 3$, assessment at a single wavelength appeared to successfully identify the few individuals having the highest concentrations of zingiberene. Thus, measurement of leaflet wash absorbance at $270 \mathrm{~nm}$ is probably adequate for identifying these relatively rare individuals in an F2 population if observations are confirmed by adequate replication. Use of absorbance at $270 \mathrm{~nm}$ or another single wavelength, to identify BC4F2 individuals having intermediate levels of 7-epi-zingiberene in this generation would be less reliable given the scatter of the relationship between 1.0 and 2.0 
absorbance units, and differentiation of individuals having low zingiberene vs none would have been impossible using absorbance at a single wavelength.

Based on results of UV scans of isolated 7-epi-zingiberene, 9-hydroxy zingiberene, and 9-hydroxy, 10, 11-epoxy-zingiberene, the $\lambda$ max in the 250 to $290 \mathrm{~nm}$ region is near 264 $\mathrm{nm}$. Consequently, if a plant breeder intends to use single-wavelength spectrophotometry as a selection tool, the choice of $264 \mathrm{~nm}$ is supported and would result in greatest sensitivity (steepest slope between compound concentration and absorbance). However, the choice of $270 \mathrm{~nm}$, the wavelength used by XX or another wavelength near $264 \mathrm{~nm}$ would have somewhat less sensitivity because zingiberenoids have a broad as opposed to narrow peak at $264 \mathrm{~nm}$ but would have similar accuracy.

Because the relationship between quantities of 7-epizingiberene, 9-hydroxy-zingiberene or 9-hydroxy, 10, 11- epoxy-zingiberene and absorbance at $264 \mathrm{~nm}$ were so similar indicates that molar absorptivity values of the three compounds are very similar. However, information on molar absorptivity can be improved by evaluation of compounds of high purity Also, additional work can be done to better pinpoint the exact wavelength of maximum absorbance of each compound, by conducting slower scans at increments of less than $1.0 \mathrm{~nm}$ on purified compounds, similar to that was accomplished for $\beta$-phellandrene [45]. The similarity of $\lambda$ max values and molar absorptivity values among the three zingiberenoid compounds considerably limits the usefulness of spectrophotometry in breeding for the presence and abundance of the oxidized forms of zingiberene. Breeding for oxidized forms is likely because allelochemical activities of the oxidized forms appear to differ, and in some cases, are better than those associated with 7-epi-zingiberene [21,5557].

Reliable quantitation by spectrophotometry generally requires that the relationship between absorbance and quantity of compound pass through the origin. In other words, the predicted intercept should be 0 so that an absorbance of 0 should indicate the absence of the compound of interest. This condition was not met for any of the plant generations evaluated by a single wavelength in this research; in all cases the intercept was significantly different from 0 . The presence of a non-zero intercept is likely due to the presence of non-target compounds in the leaflet washes that contribute absorbance at the wavelength of interest. The presence of a non-zero intercept severely limits the use of single wavelength spectrophotometry for quantitation of 7-epizingiberene in leaflet washes.

Scanning leaflet washes in the $200-350 \mathrm{~nm}$ region and recording the results provides additional, valuable data on the leaflet washes and a path for improving estimates of zingiberene content by use of multiple wavelengths to predict zingiberene content. We have provided an approach that permits identification of these pivotal wavelengths in an objective manner by use of stepwise regression and have demonstrated that their use can lead to improved estimates of zingiberene content. Unfortunately, the wavelengths chosen by this approach were not uniform among generations, likely indicating that the nontarget compounds also differed among sampled generations. Thus, any future use of this approach will require validation on the particular generation. It is likely that validation can take place on a small random sample of the population, and then the entire generation can be evaluated at the designated wavelengths. In addition to permitting identification of critical wavelengths, recorded UV scans permit calculation of average absorption spectrum for the generation, and also permit identification of the regional $\lambda$ max for each individual. Subtle shifts of $\lambda$ max values of the average spectrum or for individual spectra likely indicates the presence non-target compounds contributing to absorbance in the 264 $\mathrm{nm}$ region of the spectra.

Based on our results, the use of spectrophotometry in a tomato breeding program designed to introgress 7-epi-zingiberene from wild to cultivated tomato is a useful tool if the goal is to choose in a widely segregating population, the plant with the highest concentration of zingiberene for use in subsequent backcrosses. This is mainly related to the speed and minimal cost of spectrophotometry. If the objective is to identify individuals having intermediate, low or zero levels of zingiberene, or to introgress oxidized forms of zingiberene, the utility of single wavelength spectrophotometry is considerably reduced. 
Multiple wavelength spectrophotometry may be useful for improving quantitation of zingiberene, and to identify individuals with low or no zingiberene. But, doing so requires the ability to actually quantitate the compounds of interest by methods such as GC-FID. Also, any research designed to evaluated zingiberenoid-arthropod interactions should rely on direct quantitation of these compounds and not on spectrophotometry. Spectrophotometry can play a role in all of these activities, but quantitation of zingiberenoids must rely on other methods. Lastly, because zingiberene occurs widely in the plant kingdom, and may have health benefits, those researchers interested in quantitation of zingiberene or its oxidized forms my find utility in the measurement of absorbance at $264 \mathrm{~nm}$, similar to the ability to quantify isolated $\beta$-phellandrene [45].

Author Contributions: The authors contributed equally to conceptualization, methodology, formal analysis, investigation, writing, and visualization. All authors have read and agreed to the published version of the manuscript.

Funding: This research was funded by US Department of Agriculture, National Institute of Food and Agriculture, grant number KY011044 to JCS.

Data Availability Statement: Data is contained within the article in the regression figures. Small amounts of seed of the tomato generations mentioned in the manuscript are available for distribution to qualified tomato breeders.

Acknowledgments: The authors would like to thank Dr. Kenneth F. Haynes, a professor in the Department of Entomology at the University of Kentucky, for his assistance during lab analysis. They also thank Dr. George F. Antonious, a professor in Division of Environmental Studies, College of Agriculture, Communities, and the Environment, Kentucky State University, for his assistance. The technical assistance of Belinda Labadie in the performance of this research is greatly appreciated.

Conflicts of Interest: The authors declare no conflict of interest.

\section{References}

1. Vernin, G.; Parkanyl, C. Chemistry of ginger. Ginger: The genus zingiber, Boca Raton, FL, USA 2005, 87-180.

2. Papousek, A. Ueber das flüchtige Oel des Ingwer. Journal für Praktische Chemie 1853, 58, 228-230.

3. Eschenmoser, A.; Schinz, H. Zur Kenntnis der Sesquiterpene und Azulene. 91. Mitteilung. Zur Konstitution des Zingiberens. Helvetica Chimica Acta 1950, 33, 171-177.

4. Munda, S.; Dutta, S.; Haldar, S.; Lal, M. Chemical analysis and therapeutic uses of ginger (Zingiber officinale Rosc.) Essential Oil: A Review. Journal of Essential Oil Bearing Plants 2018, 21, 994-1002.

5. Bou, D.D.; Lago, J.H.G.; Figueiredo, C.R.; Matsuo, A.L.; Guadagnin, R.C.; Soares, M.G.; Sartorelli, P. Chemical composition and cytotoxicity evaluation of essential oil from leaves of Casearia sylvestris, its main compound $\alpha$-zingiberene and derivatives. Molecules 2013, 18, 9477-9487.

6. da Silva, M.H.L.; Andrade, E.H.A.; Zoghbi, M.d.G.B.; Luz, A.I.R.; da Silva, J.D.; Maia, J.G.S. The essential oils of Lantana camara L. occurring in North Brazil. Flavour and Fragrance Journal 1999, 14, 208-210.

7. Velasco-Negueruela, A.; Perez-Alonso, M.; de Paz, P.P.; Pala-Paul, J.; Sanz, J. Analysis by gas chromatography-mass spectrometry of the essential oils from the aerial parts of Pimpinella anagodendron Bolle and Pimpinella rupicola Svent., two endemic species to the Canary Islands, Spain. Journal of Chromatography A 2005, 1095, 180-184.

8. Ogunwande, I.A.; Walker, T.M.; Bansal, A.; Setzer, W.N.; Essien, E.E. Essential oil constituents and biological activities of Peristrophe bicalyculata and Borreria verticillata. Natural Product Communications 2010, 5, 1934578X1000501125.

9. Schnee, C.; Köllner, T.G.; Held, M.; Turlings, T.C.; Gershenzon, J.; Degenhardt, J. The products of a single maize sesquiterpene synthase form a volatile defense signal that attracts natural enemies of maize herbivores. Proceedings of the National Academy of Sciences 2006, 103, 1129-1134.

10. Zhuang, X.; Köllner, T.G.; Zhao, N.; Li, G.; Jiang, Y.; Zhu, L.; Ma, J.; Degenhardt, J.; Chen, F. Dynamic evolution of herbivore - induced sesquiterpene biosynthesis in sorghum and related grass crops. The Plant Journal 2012, 69, 70-80.

11. Maia, J.G.S.; Maria das Graças, B.Z.; Andrade, E.H.A.; da Silva, M.H.L.; Luz, A.I.R.; da Silva, J.D. Essential oils composition of Eupatorium species growing wild in the Amazon. Biochemical Systematics and Ecology 2002, 30, $1071-1077$.

12. Ogunwande, I.A.; Sonibare, M.A.; Thang, T.D.; Dung, N.X.; Soladoye, M.O.; Morohunfolu, O.O. Comparative analysis of the oils of three Ficus species from Nigeria. Journal of Essential Oil Research 2008, 20, 386-389.

13. Lundgren, L.; Norelius, C.; Stenhagen, G. Leaf volatiles from some wild tomato species. Nordic Journal of Botany 1985, 5 , 315-320.

14. Breeden, D.C.; Coates, R.M. 7-Epizingiberene, A novel bisabolane sesquiterpene from wild tomato leaves. Tetrahedron 1994, 50, 11123-11132.

15. Falara, V.; Akhtar, T.A.; Nguyen, T.T.; Spyropoulou, E.A.; Bleeker, P.M.; Schauvinhold, I.; Matsuba, Y.; Bonini, M.E.; Schilmiller, A.L.; Last, R.L. The tomato terpene synthase gene family. Plant Physiology 2011, 157, $770-789$.

16. Blázquez, M.A. Role of natural essential oils in sustainable agriculture and food preservation. Journal of Scientific Research and Reports 2014, 1843-1860.

17. Choi, W.-S.; Park, B.-S.; Ku, S.-K.; Lee, S.-E. Repellent activities of essential oils and monoterpenes against Culex pipiens pallens. Journal of the American Mosquito Control Association 2002, 18, 348-351.

18. Reis, S.L.; Mantello, A.G.; Macedo, J.M.; Gelfuso, E.A.; Da Silva, C.P.; Fachin, A.L.; Cardoso, A.M.; Beleboni, R.O. Typical monoterpenes as insecticides and repellents against stored grain pests. Molecules 2016, 21, 258. 
19. Bleeker, P.M.; Diergaarde, P.J.; Ament, K.; Schütz, S.; Johne, B.; Dijkink, J.; Hiemstra, H.; de Gelder, R.; de Both, M.T.; Sabelis, M.W. Tomato-produced 7-epizingiberene and R-curcumene act as repellents to whiteflies. Phytochemistry 2011, 72, 68-73.

20. Carter, C.D.; Sacalis, J.N.; Gianfagna, T.J. Zingiberene and resistance to Colorado potato beetle in Lycopersicon hirsutum $\mathrm{f}$. hirsutum. Journal of Agricultural and Food Chemistry 1989, 37, 206-210.

21. Dawood, M.H.; Snyder, J.C. The alcohol and epoxy alcohol of zingiberene, produced in trichomes of wild tomato, are more repellent to spider mites than zingiberene. Frontiers in Plant Science 2020, 11, 35.

22. de Azevedo, S.M.; Faria, M.V.; Maluf, W.R.; de Oliveira, A.C.B.; de Freitas, J.A. Zingiberene-mediated resistance to the South American tomato pinworm derived from Lycopersicon hirsutum var. hirsutum. Euphytica 2003, 134, $347-351$.

23. de Freitas, J.; Maluf, W.; Cardoso, M.d.G.; de Oliveira, A. Selection of tomato plant resistant to arthropod pests mediated by zingiberene. Acta Scientiarum 2000, 22, 919-923.

24. de Sena Fernandes, M.E.; Fernandes, F.L.; Silva, N.O.; da Silva, D.J.H.; Pinto, F.G.; Ramos, R.S. Selection of tomato hybrids with zingiberene concentration for breeding programs to pest resistance. Journal of A gricultural Science 2014, 6, 148.

25. Lima, I.; Resende, J.; Oliveira, J.; Faria, M.; Resende, N.; Lima-Filho, R. Indirect selection of industrial tomato genotypes rich in zingiberene and resistant to Tuta absoluta Meyrick. Genetics and Molecular Research 2015, 14, 15081-15089.

26. Resende, J.; da Silva, A.; Gabriel, A.; Zeist, A.; Favaro, R.; Nascimento, D.; Zeist, R.; Camargo, C. Resistance to Helicoverpa armigera mediated by zingiberene and glandular trichomes in tomatoes for industrial processing. Genetics and Molecular Research 2018, 17.

27. Snyder, C.J.; Dawood, M.H.S.A.; Al-Bayati, A.S. Introgression of zingiberene and type IV trichome density from Solanum habrochaites LA2329 into S. lycopersicum - Progress Report Availabe online: http://tgc.ifas.ufl.edu/TBRT\%202018/TBRT Program Book Final.pdf (accessed on June 2).

28. Butu, M.; Butnariu, M.; Rodino, S.; Butu, A. Study of zingiberene from Lycopersicon esculentum by mass spectometry. Digest Journal of Nanomaterials \& Biostructures 2014, 9.

29. Hu, S.-X.; Yu, J.-G.; Zeng, E. A theoretical study on UV-spectroscopy, electronic structure and reactivity properties of sesquiterpenes. Atmospheric Chemistry and Physics Discussions 2010, 10, 24325-24343.

30. Lange, W.H.; Bronson, L. Insect pests of tomatoes. Annual Review of Entomology 1981, 26, 345-371.

31. Zeist, A.R.; da Silva, A.A.; de Resende, J.T.V.; Maluf, W.R.; Gabriel, A.; Zanin, D.S.; Guerra, E.P. Tomato Breeding for Insect-Pest Resistance. In Recent Advances in Tomato Breeding and Production, IntechOpen: 2018; pp. 1-20.

32. Ansari, M.S.; Moraiet, M.A.; Ahmad, S. Insecticides: impact on the environment and human health. In Environmental Deterioration and Human Health, Springer: 2014; pp. 99-123.

33. Weaver, R.D.; Evans, D.J.; Luloff, A. Pesticide use in tomato production: Consumer concerns and willingness - to - pay. Agribusiness 1992, 8, 131-142.

34. Racke, K.D. Degradation of organophosphorus insecticides in environmental matrices. In Organophosphates Chemistry, Fate, and Effects, Chambers, J.E., Levi, P.E., Eds. Academic Press: San Diego, 1992; pp. 47-52.

35. Maluf, W.R.; de Fátima Silva, V.; das Graças Cardoso, M.; Gomes, L.A.A.; Neto, Á.C.G.; Maciel, G.M.; Nízio, D.A.C. Resistance to the South American tomato pinworm Tuta absoluta in high acylsugar and/or high zingiberene tomato genotypes. Euphytica 2010, 176, 113-123.

36. Dias, D.; Resende, J.; Faria, M.; Camargo, L.; Chagas, R.; Lima, I. Selection of processing tomato genotypes with high acyl sugar content that are resistant to the tomato pinworm. Genetics and Molecular Research 2013, 12, 381-389.

37. Snyder, J.C.; Simmons, A.M.; Thacker, R.R. Attractancy and ovipositional response of adult Bemisia argentifolii (Homoptera: Aleyrodidae) to type IV trichome density on leaves of Lycopersicon hirsutum grown in three day-length regimes. Journal of Entomological Science 1998, 33, 270-281.

38. Bleeker, P.M.; Mirabella, R.; Diergaarde, P.J.; VanDoorn, A.; Tissier, A.; Kant, M.R.; Prins, M.; de Vos, M.; Haring, M.A.; Schuurink, R.C. Improved herbivore resistance in cultivated tomato with the sesquiterpene biosynthetic pathway from a wild relative. Proceedings of the National Academy of Sciences 2012, 109, 20124-20129.

39. Carter, C.D.; Gianfagna, T.J.; Sacalis, J.N. Sesquiterpenes in glandular trichomes of a wild tomato species and toxicity to the Colorado potato beetle. Journal of Agricultural and Food Chemistry 1989, 37, 1425-1428.

40. Lin, S.Y.; Trumble, J.T.; Kumamoto, J. Activity of volatile compounds in glandular trichomes of Lycopersicon species against two insect herbivores. Journal of Chemical Ecology 1987, 13, 837-850.

41. Chatzivasileiadis, E.A.; Boon, J.J.; Sabelis, M.W. Accumulation and turnover of 2-tridecanone in Tetranychus urticae and its consequences for resistance of wild and cultivated tomatoes. Experimental and Applied Acarology 1999, 23, 1011-1021, doi:10.1023/a:1006394109643.

42. Antonious, G.F.; Kochhar, T.S. Zingiberene and curcumene in wild tomato. Journal of Environmental Science and Health, Part B 2003, 38, 489-500.

43. Snyder, J.C.; Thacker, R.R.; Zhang, X. Genetic transfer of a twospotted spider mite (Acari: Tetranychidae) repellent in tomato hybrids. Journal of Economic Entomology 2005, 98, 1710-1716.

44. Formighieri, C.; Melis, A. Regulation of $\beta$-phellandrene synthase gene expression, recombinant protein accumulation, and monoterpene hydrocarbons production in Synechocystis transformants. Planta 2014, 240, 309-324.

45. Melis, A.; Davies, F.K.; Wintz, H.-c.C.; Zurbriggen, A. Production of $\beta$-phellandrene using genetically engineered cyanobacteria. 9,951,354, 2018.

46. Freitas, J.A.; Maluf, W.R.; das Graças Cardoso, M.; Gomes, L.A.A.; Bearzotti, E. Inheritance of foliar zingiberene contents and their relationship to trichome densities and whitefly resistance in tomatoes. Euphytica 2002, 127, 275-287, doi:10.1023/a:1020239512598.

47. Lima, I.P.; Resende, J.T.; Oliveira, J.R.; Faria, M.V.; Dias, D.M.; Resende, N.C. Selection of tomato genotypes for processing with high zingiberene content, resistant to pests. Horticultura Brasileira 2016, 34, 387-391.

48. Coates, R.M.; Denissen, J.F.; Juvik, J.A.; Babka, B.A. Identification of $\alpha$-santalenoic and endo $\beta$-bergamotenoic acids as moth oviposition stimulants from wild tomato leaves. The Journal of Organic Chemistry 1988, 53, 2186-2192.

49. Snyder, J.C.; Guo, Z.; Thacker, R.; Goodman, J.P.; Pyrek, J.S. 2,3-Dihydrofarnesoic acid, a unique terpene from trichomes of Lycopersicon hirsutum, repels spider mites. Journal of Chemical Ecology 1993, 19, 2981-2997, doi:10.1007/bf00980597.

50. Rick, C.M. Fruit and pedicel characters derived from Galápagos tomatoes. Economic Botany 1967, 21, 171-184.

51. University Of Kentucky, Department of Horticulture. Availabe online: http://www2.ca.uky.edu/agcomm/pubs/ID/ID36/ID36.pdf (accessed on February 15. 2017).

52. Schneider, C.A.; Rasband, W.S.; Eliceiri, K.W. NIH Image to ImageJ: 25 years of image analysis. Nature Methods 2012, 9 , 671-675.

53. Glagovich, N. UV/Vis Spectroscopy, Woodward-Fieser Rules for Dienes. Availabe online: https://web.archive.org/web/20080410041714/http:/www.chemistry.ccsu.edu/glagovich/teaching/316/uvvis/diene.html (accessed on September 17, 2016). 
54. Schilmiller, A.L.; Schauvinhold, I.; Larson, M.; Xu, R.; Charbonneau, A.L.; Schmidt, A.; Wilkerson, C.; Last, R.L.; Pichersky, E. Monoterpenes in the glandular trichomes of tomato are synthesized from a neryl diphosphate precursor rather than geranyl diphosphate. Proceedings of the National Academy of Sciences 2009, 106, 10865-10870.

55. AL-Bayati, A.S. Breeding for tomato resistance to spider mite Tetranychus urticae Koch (Acari: Tetranychidae). University of Kentucky, Lexington, KY, 2019.

56. Zabel, S.; Brandt, W.; Porzel, A.; Athmer, B.; Bennewitz, S.; Schäfer, P.; Kortbeek, R.; Bleeker, P.; Tissier, A. A single cytochrome P450 oxidase from Solanum habrochaites_sequentially oxidizes 7-epi-zingiberene to derivatives toxic to whiteflies and various microorganisms. The Plant Journal 2021, 105, 1309-1325.

57. Zabel, S.; Brandt, W.; Porzel, A.; Athmer, B.; Kortbeek, R.W.; Bleeker, P.M.; Tissier, A.F. Two novel 7-epi-zingiberene derivatives with biological activity from Solanum habrochaites are produced by a single cytochrome P450 monooxygenase (Preprint). In Biorxiv, 2020. 